\title{
Activity-Dependent Myelination of Parvalbumin Interneurons Mediated by Axonal Morphological Plasticity
}

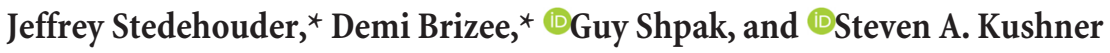 \\ Department of Psychiatry, Erasmus MC Rotterdam, The Netherlands
}

\begin{abstract}
Axonal myelination of neocortical pyramidal neurons is modulated dynamically by neuronal activity. Recent studies have shown that a substantial proportion of neocortical myelin content is contributed by fast-spiking, parvalbumin (PV)-positive interneurons. However, it remains unknown whether the myelination of $\mathrm{PV}^{+}$interneurons is also modulated by intrinsic activity. Here, we used cell-type-specific Designer Receptors Exclusively Activated by Designer Drugs (DREADDs) in adult mice to activate a sparse population of medial prefrontal cortex (mPFC) $\mathrm{PV}^{+}$interneurons. Using single-cell axonal reconstructions, we found that DREADD-stimulated $\mathrm{PV}^{+}$interneurons exhibited a nearly two-fold increase in total length of myelination, predominantly mediated by a parallel increase of axonal arborization and number of internodes. In contrast, the distribution of axonal interbranch segment distance and myelin internode length were not altered significantly. Topographical analysis revealed that myelination of DREADD-stimulated cells extended to higher axonal branch orders while retaining a similar interbranch distance threshold for myelination. Together, our results demonstrate that chemogenetically induced neuronal activity increases the myelination of neocortical $\mathrm{PV}^{+}$interneurons mediated at least in part by an elaboration of their axonal morphology.
\end{abstract}

Key words: interneuron; myelination; parvalbumin; plasticity; axon

Significance Statement

Myelination is the wrapping of an axon to optimize conduction velocity in an energy-efficient manner. Previous studies have shown that myelination of neocortical pyramidal neurons is experience and activity dependent. We now show that activitydependent myelin plasticity in the adult neocortex extends to parvalbumin (PV)-expressing fast-spiking interneurons. Chemogenetic stimulation of $\mathrm{PV}$ interneurons in the medial prefrontal cortex ( $\mathrm{mPFC}$ ) significantly enhanced axonal myelination, which was paralleled by an increase in axonal arborization. This suggests that activity-dependent axonal plasticity may involve changes in both structural morphology and myelination. Such multicomponent plasticity reveals an unexpected repertoire of anatomical parameters available for optimizing and adapting neuronal networks in response to experience.

\section{Introduction}

Myelin functions critically to enable complex neuronal function, including learning and cognition. Recent studies have shown that a substantial fraction of myelin in the cerebral cortex is localized to fast-spiking, parvalbumin-positive $\left(\mathrm{PV}^{+}\right)$interneurons (Micheva et al., 2016; Stedehouder et al., 2017). $\mathrm{PV}^{+}$interneuron myelination is topographically biased toward the proximal axon and constrained by local axonal morphology, including branch points and en passant boutons (Stedehouder et al., 2017).

Received Jan. 8, 2018; revised Feb. 21, 2018; accepted Feb. 27, 2018.

Author contributions: J.S. and D.B. wrote the first draft of the paper; J.S., D.B., and S.A.K. edited the paper; J.S., D.B., and S.A.K. designed research; J.S., D.B., and G.S. performed research; J.S. and D.B. analyzed data; J.S., D.B., and S.A.K. wrote the paper.

*J.S. and D.B. contributed equally to this work.

Correspondence should be addressed to Steven A. Kushner, Department of Psychiatry, Erasmus MC, Rotterdam 3015 CE, The Netherlands. E-mail: s.kushner@erasmusmc.nl.

DOI:10.1523/JNEUROSCI.0074-18.2018

Copyright $\odot 2018$ the authors $\quad 0270-6474 / 18 / 383631-12 \$ 15.00 / 0$
In addition, recent studies have shown that myelination is activity dependent (Fields, 2015; Chang et al., 2016). Optogenetic neuronal stimulation increases oligodendrogenesis and myelination selectively in mice (Gibson et al., 2014) and neuronal activity biases axonal selection and myelin topography in zebrafish (Hines et al., 2015; Mensch et al., 2015). Complex motor skill learning requires the production of new oligodendrocytes (McKenzie et al., 2014), monocular deprivation leads to both oligodendrogenesis and reduced internode length (Etxeberria et al., 2016), and social isolation negatively influences oligodendrocyte morphological complexity with a concomitant reduction of internode density and g-ratio (Makinodan et al., 2012).

An important outstanding question is whether $\mathrm{PV}^{+}$interneuron myelination is similarly dependent upon neuronal activity. In the present study, we use cell-specific Designer Receptor Exclusively Activated by Designer Drug (DREADD) technology to confirm that activity-dependent myelination extends to $\mathrm{PV}^{+}$interneurons in the adult brain. Electrophysiological re- 
a rAAV5/hSyn-DIO-hM3Dq-mCherry
and rAAV5/hSyn-DIO-GFP

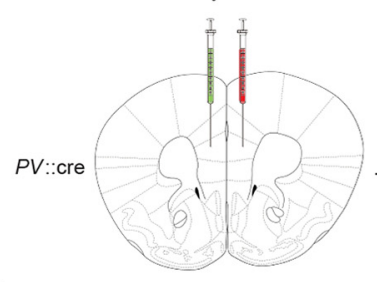

b

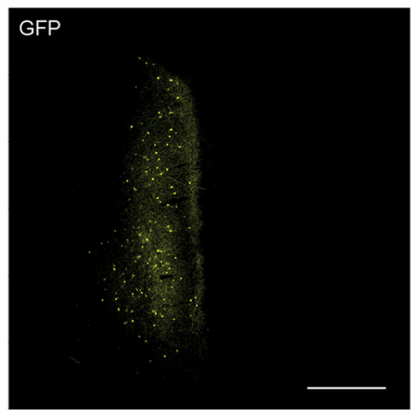

d
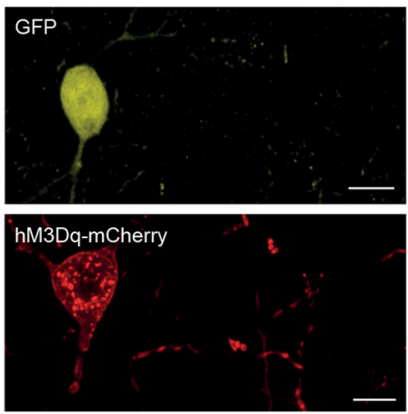

Twice-Daily CNO Injections

14 days

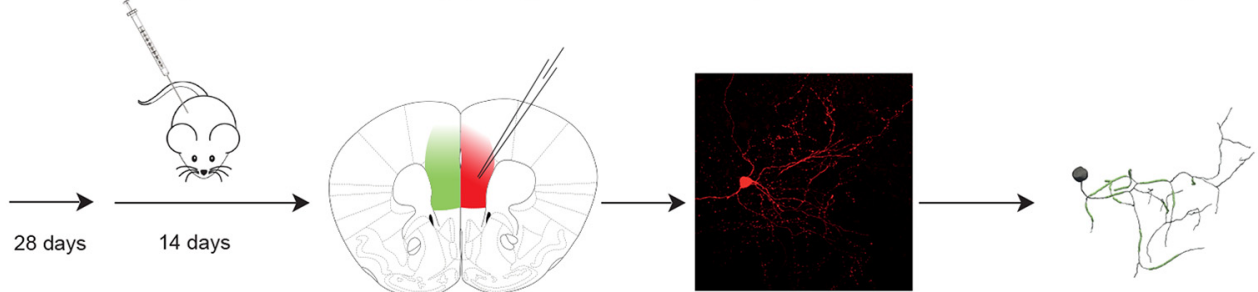

Whole-Cell Electrophysiology
Confocal Imaging

Biocytin-Filled Cell
Reconstruction Proximal

Axon With Myelin
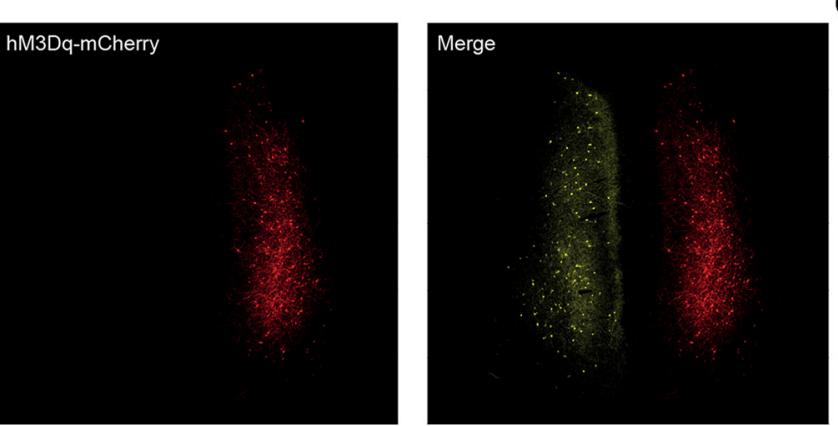

C

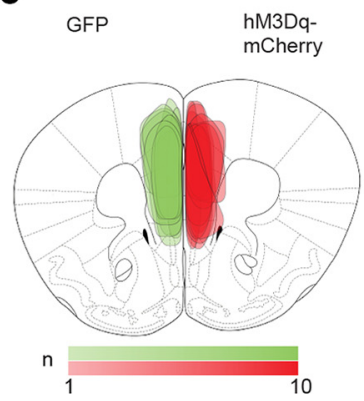

e
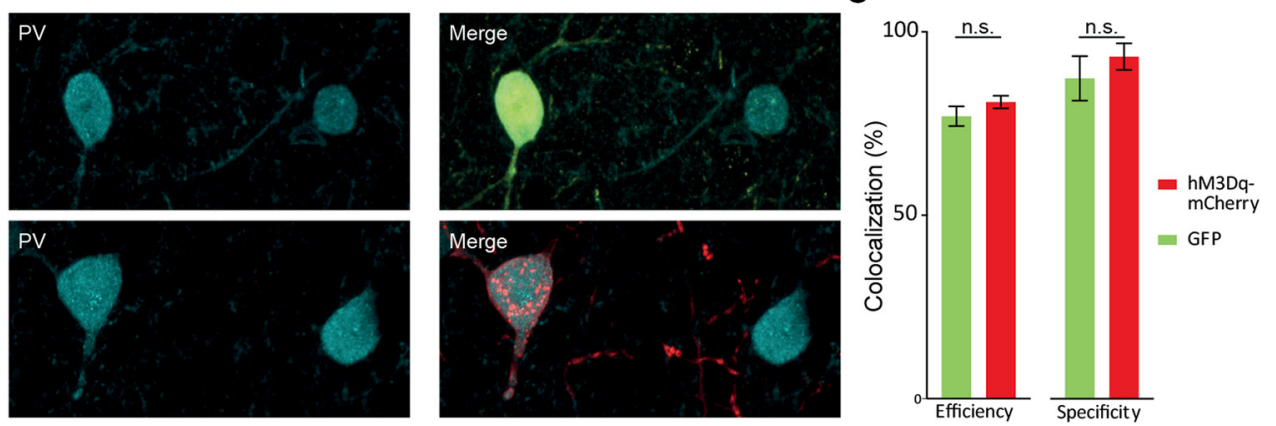

Figure 1. $\quad \mathrm{PV}^{+}$interneuron-specific DREADD expression. $\boldsymbol{a}$, Experimental design. Adult $P V:: c$ cre mice were virally transduced with pseudorandomly assigned unilateral hM3Dq-mCherry and contralateral GFP. Twenty-eight days after surgery, mice were injected twice daily with $1 \mathrm{mg} / \mathrm{kg}$ CNO intraperitoneally for $14 \mathrm{~d}$. One day after the last injection, mice were killed and labeled cells were recorded electrophysiologically in whole-cell configuration. Biocytin-filled cells were imaged and axons were reconstructed including myelination. $\boldsymbol{b}$, Representative low-magnification confocal image of a bilateral injection of hM3Dq-mCherry (red) and GFP (yellow) at $+2.1 \mathrm{~mm}$ from bregma. Scale bar, $500 \mu \mathrm{m}$. c, Schematic projection of injection areas from $n=10$ mice for hM3Dq-mCherry (red) and GFP (green), with color intensity indicating number of mice. $\boldsymbol{d}$, Top, Maximum projection confocal image of colocalized GFP (yellow) and PV (cyan) immunofluorescence. Scale bar, $10 \mu \mathrm{m}$. Bottom, Maximum projection confocal image of colocalized hM3Dq-mCherry (red) and PV (cyan) immunofluorescence. Scale bar, $10 \mu \mathrm{m}$. $\boldsymbol{e}$, Quantification of colocalization between hM3Dq-mCherry (red), GFP (green) and PV immunofluorescence. Transduction efficiency was similarly high for both vectors $\left[\mathrm{P}\left(\mathrm{GFP}{ }^{+} \mid \mathrm{PV}{ }^{+}\right): 77.0 \pm 2.7 \%, \mathrm{P}\left(\mathrm{hM} 3 \mathrm{Dq}-\mathrm{mCherry}{ }^{+} \mid \mathrm{PV}{ }^{+}\right.\right.$): $\left.80.9 \pm 1.7 \% ; t_{(4)}=1.218, p=0.290\right]$. Transduction specificity was also similarly high $\left[\mathrm{P}\left(\mathrm{PV}^{+} \mid \mathrm{GFP}{ }^{+}\right): 87.6 \pm 6.1 \%, \mathrm{P}\left(\mathrm{PV}^{+} \mid \mathrm{hM} 3 \mathrm{Dq}-\mathrm{mCherry}{ }^{+}\right): 93.5 \pm 3.6 \% ; t_{(4)}=0.844, p=0.446\right] . n=$ 3 mice. Unpaired two-tailed Student's $t$ tests were used in e. Scale bars indicate mean \pm SEM. n.s., Nonsignificant.

cordings with single-cell labeling of manipulated cells permitted the coordinated examination of axonal morphology and myelin topography, revealing an activity-dependent enhancement of $\mathrm{PV}^{+}$interneuron myelination that could be largely explained by an elaboration of axonal arborization with a parallel increase of internode number.

\section{Materials and Methods}

Mice. All experiments were approved by the Dutch Ethical Committee and in accordance with the Institutional Animal Care and Use Committee guidelines. Mouse lines were obtained from The Jackson Laboratory

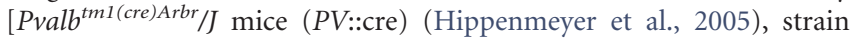
$\# 008069 ; C 57 B L / 6 J$ (WT), strain \#000664]. All lines were backcrossed for $>10$ generations in $\mathrm{C} 57 \mathrm{BL} / 6 \mathrm{~J}$. Adult mice of both genders were used from 8-12 weeks of age. Mice were group-housed and maintained on a $12 \mathrm{~h}$ light/dark cycle with ad libitum access to food and water. After surgery, mice were single-housed until further experiments.

Viral labeling and CNO injections. Heterozygous $P V:: c r e$ mice were used for viral-mediated cell-type-specific labeling performed using adeno-associated virus (AAV) expression with cre-dependent AAV5/ hSyn-DIO-hM3Dq-mCherry and AAV5/hSyn-DIO-GFP (University of
Pennsylvania Viral Vector Core). Virus was diluted to $\sim 5 \times 10^{11} \mathrm{GC} / \mathrm{ml}$ in PBS to achieve sparse labeling. hM3Dq-mCherry and GFP control injections were counterbalanced between the left and right hemisphere. All mice showed successful bilateral virus expression with no contralateral contamination.

Anesthesia was induced using $5 \%$ isoflurane $\left(\mathrm{O}_{2}\right.$ flow of $\left.0.5 \mathrm{~L} / \mathrm{min}\right)$, and subsequently maintained with $1-2 \%$ isoflurane during surgery. Body temperature was maintained at $37^{\circ} \mathrm{C}$. Mice were placed into a custom-made stereotaxic frame using a mouth bar (Stoelting) for head fixation. Analgesia was provided systemically by subcutaneous Temgesic injection (buprenorphine $0.5 \mathrm{mg} / \mathrm{kg}$ ) and locally by xylocaine spray (100 mg/ml; AstraZeneca) applied directly on the skull. To access the brain, a longitudinal scalp incision of $\sim 1 \mathrm{~cm}$ length was made to reveal the skull and a small craniotomy $(<1$ $\mathrm{mm}$ ) was performed overlying the injection sites at the following coordinates (in mm): mPFC: +1.75 bregma, \pm 0.35 lateral, -1.9 dorsoventral

Mice used for electrophysiological recordings received $1 \mu \mathrm{l}$ in a $1 / 2$ dilution. Virus was aspirated in a borosilicate glass micropipette, which was slowly lowered to the target site. Virus injection was controlled by an automated syringe pump (infusion speed $0.1 \mu \mathrm{l} / \mathrm{min}$ ). At the conclusion of the injection, the micropipette was maintained in place for another 5 min and then slowly withdrawn. The surgical wound was closed with skin 
a

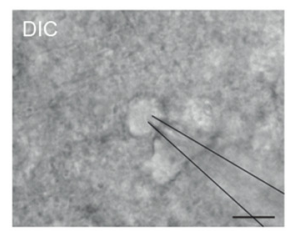

C

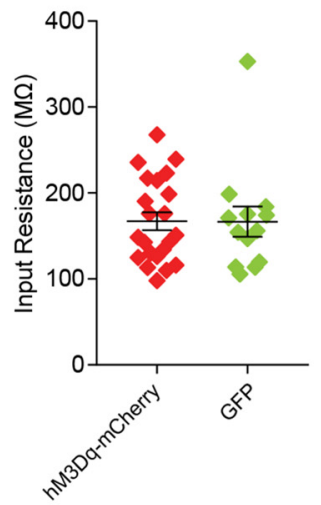

h

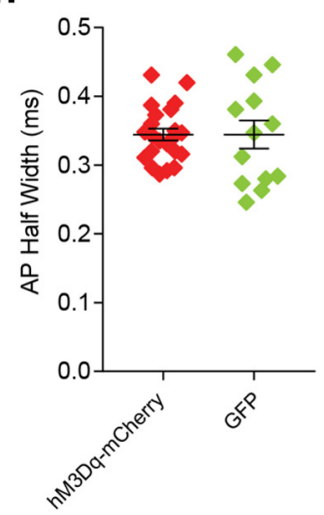

hM3Dq-mCherry

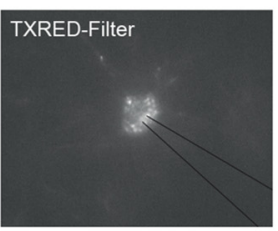

d

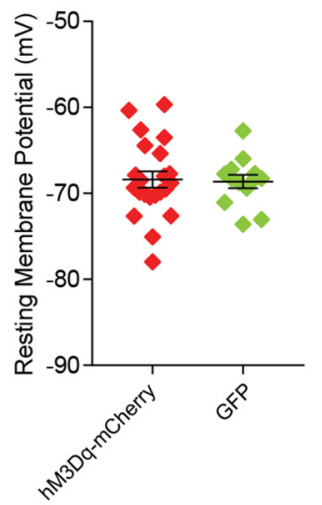

i

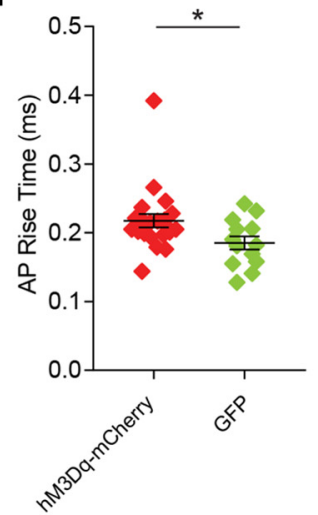

b

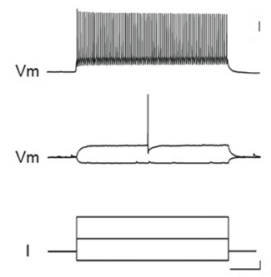

e

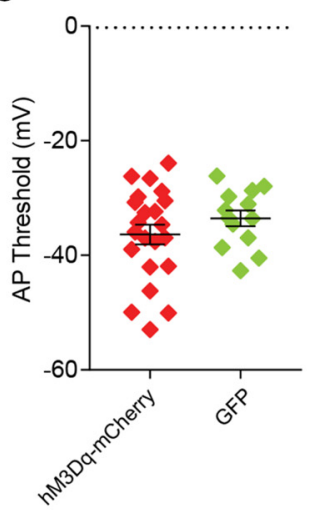

f

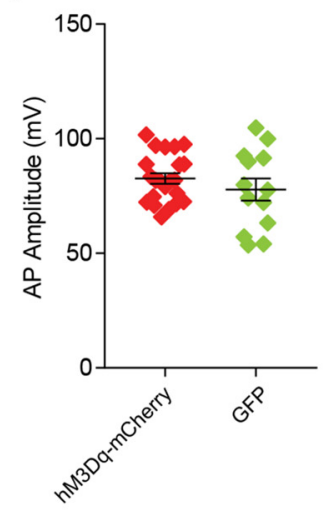

g

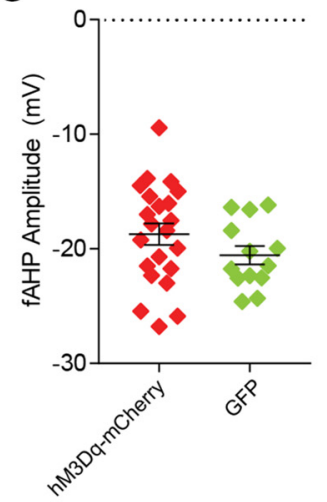

j

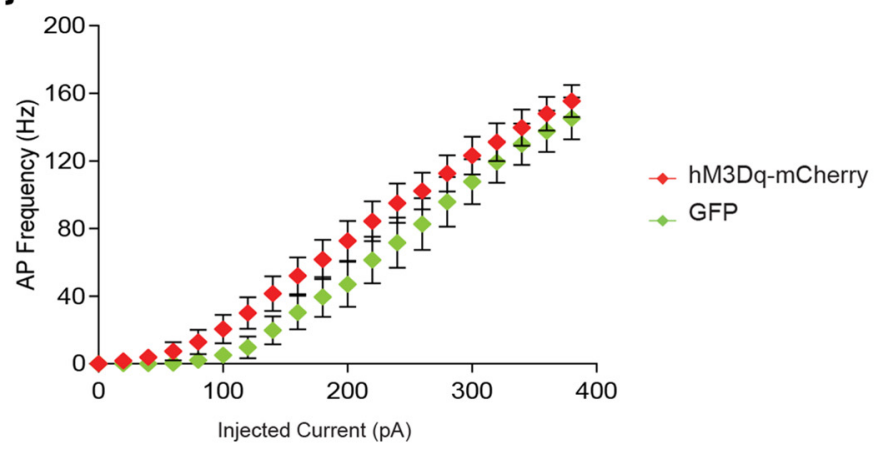

Figure 2. Fluorescence-targeted whole-cell electrophysiological recordings from hM3Dq-mCherry and contralateral GFP cells. $\boldsymbol{a}, \boldsymbol{b}$, Representative differential interference contrast (DIC) and epifluorescence images of hM3Dq-mCherry ${ }^{+}(\boldsymbol{a})$ and GFP ${ }^{+}(\boldsymbol{b})$ cells exhibiting a fast-spiking AP train. Scale bars indicate $15 \mu \mathrm{m}$ (left) and $20 \mathrm{mV}, 100 \mathrm{pA}$ and $100 \mathrm{~ms}$ from top to bottom (right). $\boldsymbol{c}-\boldsymbol{j}$, In the absence of CNO, hM3Dq-mCherry ${ }^{+}\left(n=23\right.$; red diamonds) and GFP ${ }^{+}$cells $(n=13$; green diamonds) were electrophysiologically similar: input resistance (c; hM3Dq-mCherry: $167.1 \pm$ $10.5 \mathrm{M} \Omega ; \mathrm{GFP}: 166.7 \pm 17.6 \mathrm{M} \Omega ; U=153.000, p=0.749)$, resting membrane potential (d; hM3Dq-mCherry: $\left.-68.4 \pm 1.0 \mathrm{mV} ; \mathrm{GFP}:-68.6 \pm 0.8 \mathrm{mV} ; t_{(33)}=-0.182, p=0.857\right), \mathrm{AP}$ threshold (e; hM3Dq-mCherry: $\left.-36.4 \pm 1.7 \mathrm{mV} ; \mathrm{GFP}:-33.6 \pm 1.4 \mathrm{mV} ; t_{(33)}=1.124, p=0.269\right)$, AP amplitude $\left(\boldsymbol{f}\right.$; hM3Dq-mCherry: $\left.82.6 \pm 2.3 \mathrm{mV} ; \mathrm{GFP}: 77.8 \pm 4.8 \mathrm{mV} ; t_{(33)}=-0.918, p=0.371\right)$, fAHP (g; hM3Dq-mCherry: $-18.7 \pm 0.9 \mathrm{mV}$; GFP: $\left.-20.6 \pm 0.8 \mathrm{mV} ; t_{(33)}=-1.340, p=0.189\right)$, AP half-width $\left(\boldsymbol{h} ;\right.$ hM3Dq-mCherry: $0.34 \pm 0.01 \mathrm{~ms} ;$ GFP: $0.34 \pm 0.02 \mathrm{~ms} ; t_{(33)}=0.001, p=$ 0.999). $\boldsymbol{i}$, A small increase of AP rise time was observed in $\mathrm{hM} 3 \mathrm{Dq}$-mCherry ${ }^{+}$cells (hM3Dq-mCherry: $0.22 \pm 0.01 \mathrm{~ms}$; GFP: $\left.0.19 \pm 0.01 \mathrm{M} \Omega ; U=202.500, p=0.041\right) . j$, Evoked AP firing was unchanged between $\mathrm{hM3Dq-mCherry}{ }^{+}$and GFP ${ }^{+}$cells $\left(F_{(19,570)}=0.988, p=0.473\right.$; repeated-measures ANOVA). Unpaired two-tailed Student's $t$ tests were used in $\boldsymbol{d}-\boldsymbol{h}$. Mann-Whitney two-tailed $U$ test was used for $c$ and $i$ because of non-normality. Scale bars indicate mean \pm SEM. $V_{m}$, Membrane voltage; $I$, current injection. ${ }^{*} p<0.05$.

glue (Derma + flex). Mice were left to recover for $28 \mathrm{~d}$ to allow expression of hM3Dq-mCherry and GFP protein. To optimize the bilateral virus injection symmetry necessary for consequent bilateral electrophysiology, we took particular care at a few key points: (1) mouse skulls were always carefully vertically leveled based on bregma and lambda, (2) glass micropipettes were always checked to run properly before injections and were carefully cleaned to remove excess virus particles, (3) drill holes were kept as small as possible ( $<1 \mathrm{~mm})$, and (4) mice were left to recover for exactly $28 \mathrm{~d}$ before starting clozapine $\mathrm{N}$-oxide $(\mathrm{CNO})$ injections to minimize expression variations between mice.

After $28 \mathrm{~d}$ of recovery, mice were injected intraperitoneally with $\mathrm{CNO}$ (Sigma-Aldrich) $1 \mathrm{mg} / \mathrm{kg}$ twice daily (at $\sim 9: 00 \mathrm{~h}$ and $\sim 18: 00 \mathrm{~h}$ ) for 14 consecutive days. Mice displayed no weight loss over the injection period (day 1: $26.2 \pm 1.5 \mathrm{~g}$; day 14: $24.8 \pm 1.1 \mathrm{~g} ; p=0.458$; paired two-tailed $t$ test) or overt behavioral abnormalities under $\mathrm{CNO}$ administration.
Electrophysiology. The next morning after the last $\mathrm{CNO}$ injection, mice were anesthetized using 5\% isoflurane and decapitated in ice-cold, $\mathrm{N}$-methyl-D-glucamine (NMDG)-based cutting solution containing the following (in mM): $93 \mathrm{NMDG}, 93 \mathrm{HCl}, 30 \mathrm{NaHCO}_{3}, 25$ D-glucose, 20 HEPES, $5 \mathrm{Na}$-ascorbate, 2 thiourea, $10 \mathrm{MgCl}_{2}, 3 \mathrm{Na}$-pyruvate, $2.5 \mathrm{KCl}$, $1.25 \mathrm{NaH}_{2} \mathrm{PO}_{4}$, and $0.5 \mathrm{CaCl}_{2}, 300 \mathrm{mOsm}, \mathrm{pH} 7.4$, oxygenated with $95 \%$ $\mathrm{O}_{2} / 5 \% \mathrm{CO}_{2}$. Coronal slices $(300 \mu \mathrm{m})$ were cut with a vibrating slicer (Microm HM $650 \mathrm{~V}$; Thermo Scientific) and incubated in cutting solution at $37^{\circ} \mathrm{C}$ for $8 \mathrm{~min}$, followed by oxygenated $\left(95 \% \mathrm{O}_{2} / 5 \% \mathrm{CO}_{2}\right)$ artificial CSF (aCSF) at $37^{\circ} \mathrm{C}$ for another $10 \mathrm{~min}$. ACSF contained the following (in mM): $127 \mathrm{NaCl}, 25 \mathrm{NaHCO}_{3}, 25 \mathrm{D}$-glucose, $2.5 \mathrm{KCl}, 1.25$ $\mathrm{NaH}_{2} \mathrm{PO}_{4}, 1.5 \mathrm{MgSO}_{4}$, and $1.6 \mathrm{CaCl}_{2}$. Slices were then allowed to recover at room temperature for at least $1 \mathrm{~h}$ before recordings.

$\mathrm{PV}^{+}$interneurons from the prelimbic region layer $\mathrm{V}$ of the mPFC were visualized by mCherry or GFP fluorescence using a TXRED or GFP 
filter (Semrock), respectively. Importantly, $\mathrm{GFP}^{+}$control cells were recorded from contralateral hemispheres of the same coronal slices as recorded hM3Dq-mCherry ${ }^{+}$cells and cells were recorded from equal distances from the midline (see Fig. 4d). To minimize variation in proportion of missing axon due to slicing, cells were consistently patched at a depth of $20-50 \mu \mathrm{m}$ from the slice surface. Whole-cell recordings were made using borosilicate glass pipettes (3.5-5.5 $\mathrm{M} \Omega$ resistance) with intracellular solution containing the following (in mM): $120 \mathrm{~K}$-gluconate, $10 \mathrm{KCl}, 10$ HEPES, 10 K-phosphocreatine, 4 ATP-Mg, 0.4 GTP, and 5 $\mathrm{mg} / \mathrm{ml}$ biocytin, $\mathrm{pH}$ adjusted to 7.4 using $\mathrm{KOH}$ and osmolarity 285-290 mOsm. All recorded $\mathrm{mCherry}^{+}$and $\mathrm{GFP}^{+}$cells had a fast-spiking phenotype, with subthreshold membrane potential oscillations, suprathreshold highfrequency, nonadapting firing patterns, and large-amplitude fast afterhyperpolarizations. Cells were filled for at least $25 \mathrm{~min}$ for proper biocytin spreading.

Recordings were performed in aCSF at nearphysiological temperatures $\left(33 \pm 1{ }^{\circ} \mathrm{C}\right)$ using HEKA EPC10 Quattro amplifiers and Patchmaster software $(40 \mathrm{kHz})$. Series resistance was typically $<20 \mathrm{M} \Omega$ and fully compensated for bridge balance and capacitance. No correction was made for liquid junction potential. Data analysis was performed offline using Igor Pro version 6 (Wavemetrics).

Basic physiological characteristics were determined from voltage responses to squarewave current pulses of $500 \mathrm{~ms}$ duration ranging from $-100 \mathrm{pA}$ to $+300 \mathrm{pA}$ and delivered in $20 \mathrm{pA}$ intervals. Input resistance was determined by the slope of the linear regression through the voltage-current curve. Single action potential (AP) characteristics were obtained from the first elicited AP. AP threshold was defined as the inflection point at the foot of the regenerative upstroke. AP amplitude was defined as the voltage difference between the threshold and peak voltage. AP half-width was measured at half of the peak amplitude. AP rise time was quantified as duration from $10 \%$ to $90 \%$ of the peak amplitude. The fast afterhyperpolarizing potential (fAHP) amplitude was measured as the hyperpolarizing deflection from AP threshold after AP initiation.

Local application of $\mathrm{CNO}$ was performed at a concentration of $10 \mu \mathrm{M}$ (in $0.9 \% \mathrm{NaCl}$ ) through a borosilicate glass pipette $(3.5-5.5 \mathrm{M} \Omega$ resistance). The pipette was backfilled with $\mathrm{CNO}$ and positioned at a distance of $\sim 20 \mu \mathrm{m}$ from the recorded soma within the same focal plane. A total of $50 \mu \mathrm{l}$ of CNO $(10 \mu \mathrm{M})$ was applied over $250 \mathrm{~ms}$ at a fixed rate of $200 \mu \mathrm{l} / \mathrm{s}$.

Immunofluorescence. For recovery of biocytin-labeled cells after electrophysiological recordings, $300 \mu \mathrm{m}$ slices were incubated overnight at $4^{\circ} \mathrm{C}$ in fresh $4 \%$ paraformaldehyde (PFA). Slices were extensively rinsed at room temperature in PBS and stained in PBS buffer containing 0.4\% Triton X-100, 2\% normal horse serum (NHS; Invitrogen) and streptavidinconjugated secondary antibody 488 (1:300, Jackson Laboratories; for $\mathrm{hM}$ Dq-mCherry ${ }^{+}$cells) or streptavidin-Cy3 (1:300; Invitrogen; for $\mathrm{GFP}^{+}$cells) for $5 \mathrm{~h}$ at room temperature. Slices were washed with PBS and PB $0.1 \mathrm{M}$ and mounted on slides, coverslipped with $200 \mu \mathrm{l}$ of Mowiol (Sigma-Aldrich), sealed, and immediately imaged for full axonal morphology (see "Confocal microscopy" section). To avoid excessive thinning or drying of $300 \mu \mathrm{m}$ sections, cells were mounted, imaged, and returned to PB $0.1 \mathrm{~m}$ directly after imaging.

After full cell imaging, $300 \mu \mathrm{m}$ slices were extensively washed in PB 0.1 $\mathrm{M}$ and $\mathrm{PBS}$, and subsequently incubated overnight at $4^{\circ} \mathrm{C}$ in $30 \%$ sucrose
$(0.1 \mathrm{M} \mathrm{PB})$. Sections were then carefully recut at $40 \mu \mathrm{m}$ using a freezing microtome (Leica; SM 2000R) and stored serially in $0.1 \mathrm{M} \mathrm{PB}$ at $4^{\circ} \mathrm{C}$. Forty-micrometer sections were washed with PBS and preincubated with a blocking PBS buffer containing $0.5 \%$ Triton X-100 and 10\% NHS for $1 \mathrm{~h}$ at room temperature. Sections were incubated in PBS buffer containing $0.4 \%$ Triton $\mathrm{X}-100$ and $2 \%$ NHS for $72 \mathrm{~h}$ at $4^{\circ} \mathrm{C}$ and goat anti-MBP (1:300, Santa Cruz Biotechnology, C-16, sc-13914). Then, sections were washed with PBS and incubated with corresponding Alexa Fluor-conjugated secondary antibodies (1:300, Invitrogen) and cyanine dyes (1: 300 , Sanbio) in PBS buffer containing $0.4 \%$ Triton X-100, $2 \%$ NHS for $5 \mathrm{~h}$ at room temperature. For biocytin, streptavidin-A488 (1:300; Jackson Laboratories) and streptavidin-Cy3 (1:300; Invitrogen) were again used. Nuclear staining was performed using DAPI $(1: 10,000$; Invitrogen). Sections were washed with $\mathrm{PB} 0.1 \mathrm{M}$ and mounted on slides, coverslipped with Vectashield H1000 fluorescent mounting medium (Vector Laboratories), sealed, and imaged (see "Confocal microscopy" section).

An independent group of mice received $\mathrm{CNO}$ injections for $14 \mathrm{~d}$ before transcardial perfusion using 4\% PFA. Brains were resected, placed in $4 \%$ PFA for postfixation ( $2 \mathrm{~h}$ ) at room temperature and subsequently stored in $10 \%$ sucrose solution $(0.1 \mathrm{M} \mathrm{PB})$ overnight at $4^{\circ} \mathrm{C}$. The next day, brains were embedded in gelatin ( $12 \%$ gelatin (SigmaAldrich) $/ 10 \%$ sucrose), postfixed ( $10 \% \mathrm{PFA} / 30 \%$ sucrose) for $2 \mathrm{~h}$ at room temperature, and then stored in $30 \%$ sucrose solution overnight at $4^{\circ} \mathrm{C}$. Coronal sections were made on a freezing microtome in $40 \mu \mathrm{m}$ and collected in $0.1 \mathrm{M}$ PB. Subsequently, slices were similarly stained as described above for recut electrophysiology slices.

The following primary antibodies were used: rabbit anti-mCherry (1: 500, Abcam, ab167453), chicken anti-GFP (1:2000, Aves Laboratories), mouse anti-PV (1:1000, Swant, 235), goat anti-MBP (1:300, Santa Cruz 
a

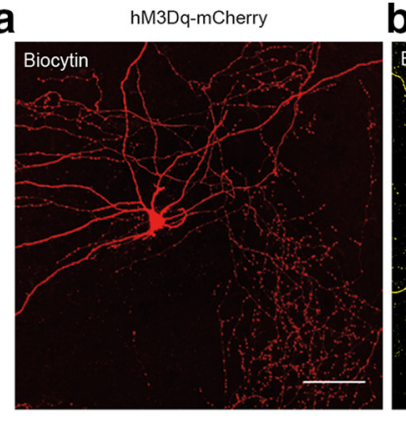

b

e
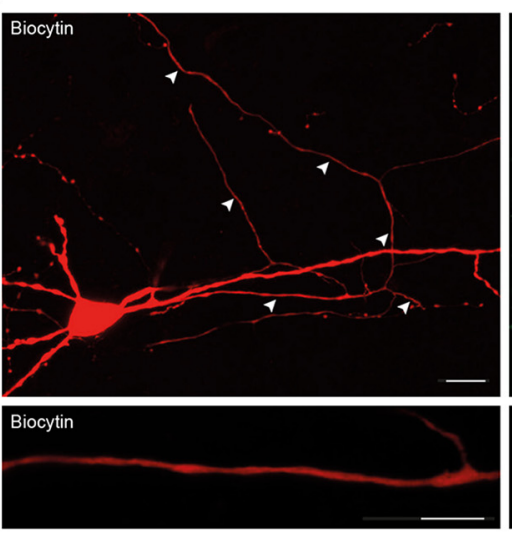

f

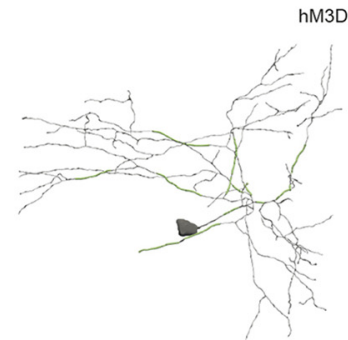

h

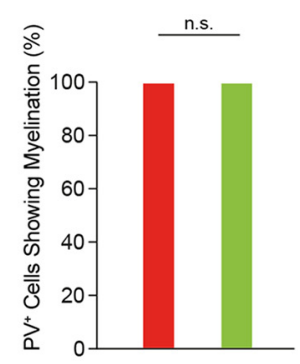

I

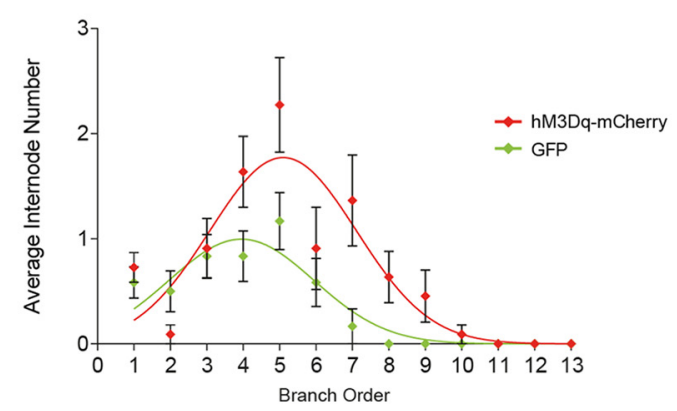

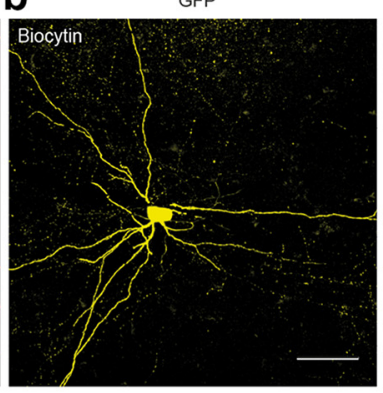

C
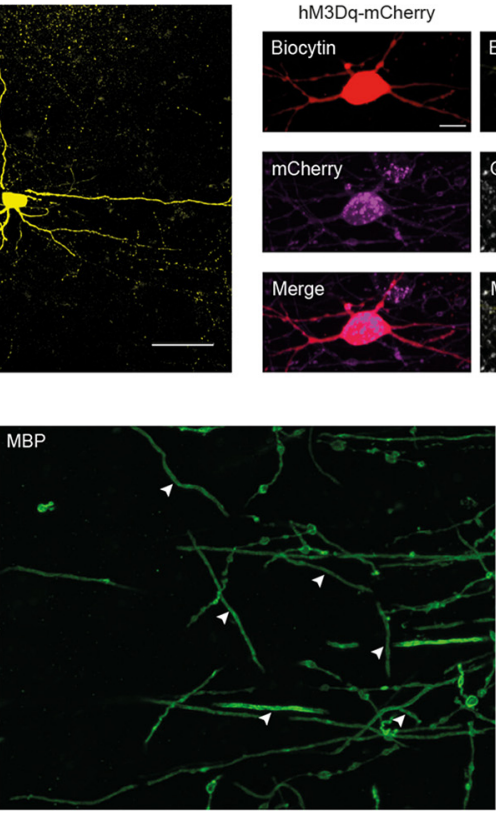

MBP

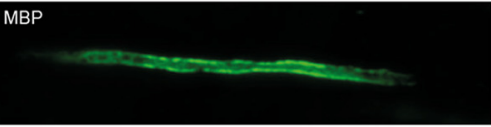

g

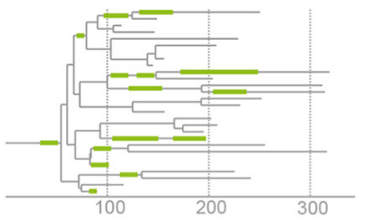

i

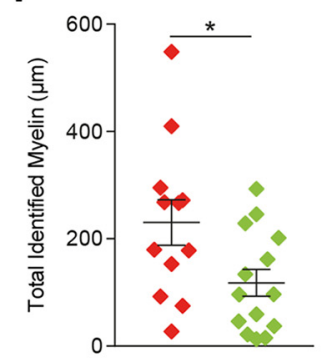

j

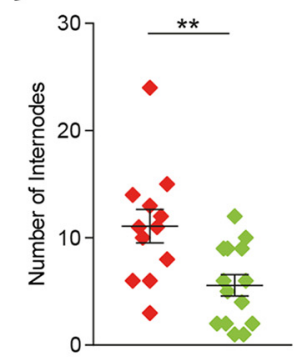

m
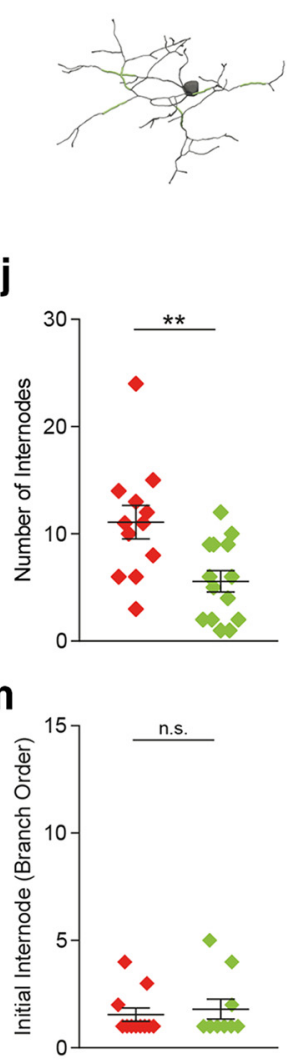

d
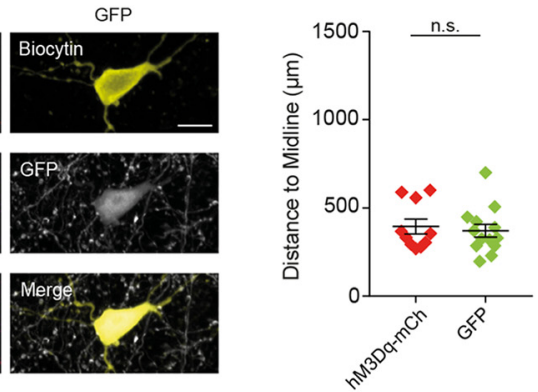

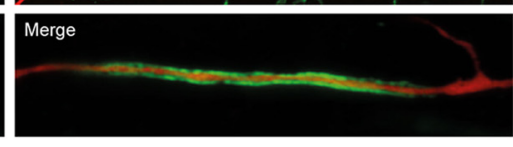

GFP

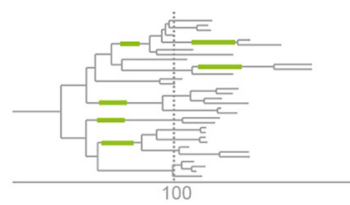

k

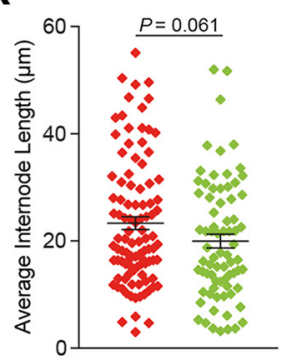

n

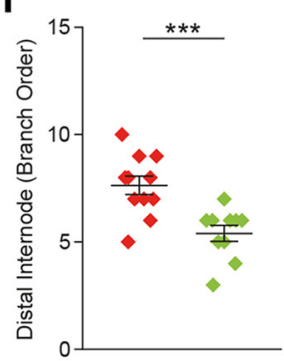

Figure 4. DREADD-activated cells have increased myelination. $\boldsymbol{a}, \boldsymbol{b}$, Maximum projection confocal images of representative biocytin-filled hM3Dq-mCherry ${ }^{+}(\boldsymbol{a} ;$; red $)$ and GFP ${ }^{+}(\boldsymbol{b}$; yellow) cells. Scale bars, $50 \mu \mathrm{m}$. c, Left, Post hoc confirmation demonstrating that putative hM3Dq-mCherry ${ }^{+}$biocytin-labeled cells (red) were hM3Dq-mCherry ${ }^{+}$(purple). Right, Post hoc confirmation that putative GFP ${ }^{+}$biocytin-labeled cells (yellow) were GFP ${ }^{+}$(gray). Scale bars, $10 \mu \mathrm{m}$. d, Reconstructed cells were located at similar cortical depths (hM3Dq-mCherry, red diamonds: $394.5 \pm 42.3$ $\mu \mathrm{m}$; GFP, green diamonds: $369.8 \pm 36.5 \mu \mathrm{m} ; U=61.000, p=0.832$ ). e, Top, Low-magnification confocal image of a biocytin-labeled $\mathrm{PV}^{+}$(Figure legend continues.) 
a

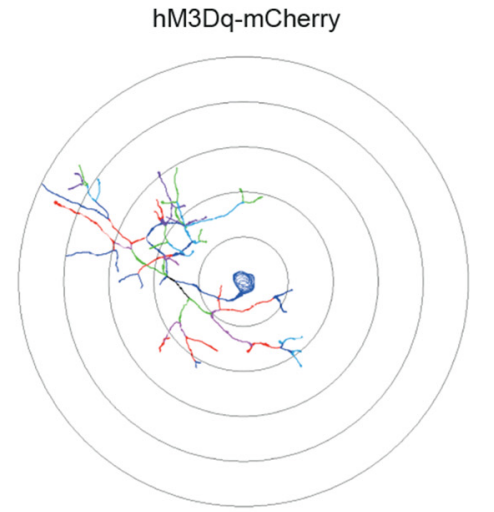

C

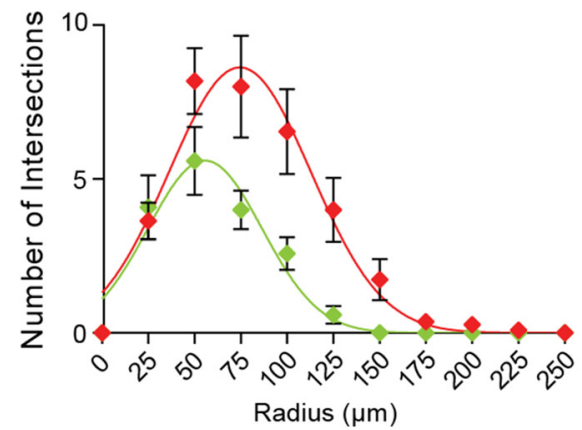

b GFP

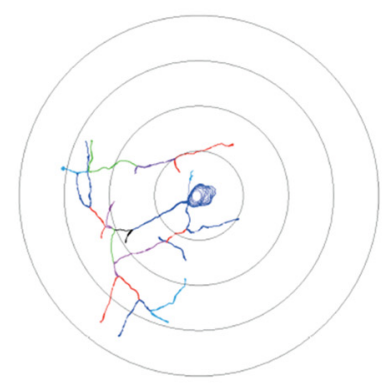

d

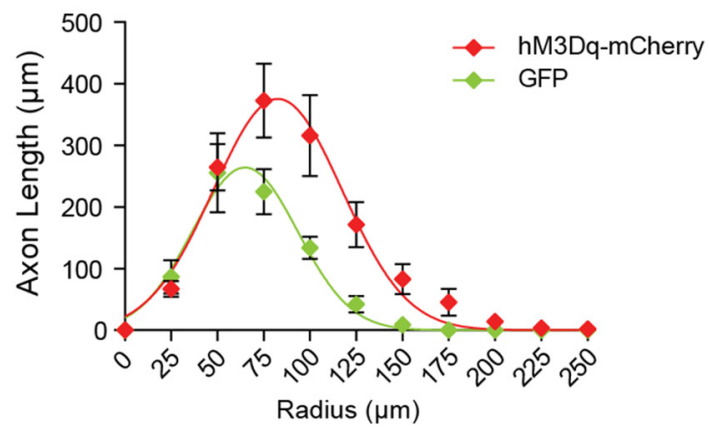

Figure 5. Sholl analysis reveals activity-dependent enhancement of proximal axonal complexity in PV ${ }^{+}$interneurons. $\boldsymbol{a}, \boldsymbol{b}$, Representative Sholl analysis for hM3Dq-mCherry ${ }^{+}(\boldsymbol{a})$ and GFP ${ }^{+}$ (b) cell axons. Radial spacing, $25 \mu \mathrm{m}$. Colors indicate distinct centrifugal branch orders. $\boldsymbol{c}, \boldsymbol{d}$, Number of intersections $\left(\boldsymbol{c} ; F_{(10,210)}=4.073, p<0.001\right.$, repeated-measures ANOVA) and axonal length $\left(\boldsymbol{d} ; F_{(6,60)}=3.664, p=0.004\right.$, repeated-measures ANOVA) were significantly increased in hM3Dq-mCherry ${ }^{+}$cells (red diamonds) compared with GFP ${ }^{+}$cells (green diamonds). Scale bars indicate SEM.

Biotechnology, C-16, sc-13914), and mouse anti-CC1 (1:100, Merck, ab-7).

Confocal imaging and analysis. Confocal imaging was performed using a Zeiss LSM 700 microscope equipped with Plan-Apochromat $10 \times / 0.45$, $20 \times / 0.8$ and $63 \times / 1.4$ (oil-immersion) objectives. DAPI, Alexa Fluor 488, Cy3, and Alexa Fluor 647 were imaged using excitation wavelengths of 405, 488, 555, and $639 \mathrm{~nm}$, respectively. Reconstructions of biocytin-

$\leftarrow$

(Figure legend continued.) interneuron (red), with myelinated internodes revealed by MBP immunofluorescence (green). Arrowheads indicate myelinated internodes belonging to the biocytin-labeled cell. Scale bar, $10 \mu \mathrm{m}$. Bottom, High-magnification confocal maximum projection image of a biocytin-labeled (red), myelinated (MBP; green) axonal segment. Scale bar, 5 $\mu \mathrm{m} . \boldsymbol{f}, \boldsymbol{g}$, Proximal axonal reconstruction (left) with indicated segmental myelination of hM3Dq-mCherry ${ }^{+}(\boldsymbol{f})$ and GFP ${ }^{+}(\boldsymbol{g})$ cells shown in $(\boldsymbol{a})$ and $(\boldsymbol{b})$, respectively, with their corresponding schematic dendrogram representationa (right). Soma and axon are shown in gray, myelin in green. Horizontal axis is in micrometers. $\boldsymbol{h}$, All examined hM3Dq-mCherry ${ }^{+}($red, $n=$ 12) and GFP ${ }^{+}$cells (green, $n=14$ ) show myelination. $\boldsymbol{i}$, hM3Dq-mCherry ${ }^{+}$cells show a higher total amount of myelin per cell compared with GFP ${ }^{+}$cells. hM3Dq-mCherry: $230.3 \pm 42.4 \mu \mathrm{m}$ myelin/cell; GFP: $117.9 \pm 25.1 \mu \mathrm{m}$ myelin/cell; $t_{(24)}=2.359, p=0.027$. $\boldsymbol{j}$, hM3Dq$\mathrm{mCherry}^{+}$cells show a greater number of internodes per cell compared with GFP ${ }^{+}$cells (hM3Dq-mCherry: $10.4 \pm 1.3$ internodes/cell; GFP: $5.6 \pm 1.0$ internodes/cell; $t_{(24)}=3.008$, $p=0.006)$. $\boldsymbol{k}_{\text {, Internode length is similar between hM3Dq-mCherry }}{ }^{+}$and $\mathrm{GFP}^{+}$cells (hM3Dq-mCherry: $23.2 \pm 1.2 \mu \mathrm{m}, n=99$ internodes; GFP: $19.9 \pm 1.3 \mu \mathrm{m}, n=75$ internodes; $\left.t_{(172)}=1.888, p=0.061\right) . I, \mathrm{hM} \mathrm{Dq}$-mCherry ${ }^{+}$cells have an increased number of internodes beginning from fourth branch order axonal segments distally $\left(F_{(12,240)}=2.890\right.$, $p<0.001$, repeated-measures ANOVA). $\boldsymbol{m}, \mathrm{hM} 3 \mathrm{Dq}$ - $\mathrm{mCherry}{ }^{+}$and GFP ${ }^{+}$cells have a similar myelination onset (hM3Dq-mCherry: $1.7 \pm 0.4 ; \mathrm{GFP}: 1.9 \pm 0.5 ; \boldsymbol{U}=89.000, p=0.574) . \boldsymbol{n}$, In contrast, the most distal branch order showing myelination is located further along the axon in hM3Dq-mCherry ${ }^{+}$cells (hM3Dq-mCherry: 7.6 $\pm 0.4 ;$ GFP: $5.3 \pm 0.3 ; t_{(21)}=4.387, p<$ $0.001) .{ }^{* * *} p<0.001{ }^{* *} p<0.01,{ }^{*} p<0.05$, n.s., Nonsignificant. Unpaired Student's twotailed $t$ test was used in $\boldsymbol{i}, \boldsymbol{j}, \boldsymbol{k}$, and $\boldsymbol{n}$; Mann-Whitney two-tailed $U$ test was in $\boldsymbol{d}$ and $\boldsymbol{m}$ because of non-normality. Scale bars indicate mean \pm SEM. filled cells were obtained from $300 \mu \mathrm{m}$ slices at $63 \times$ magnification with $1 \times$ digital zoom and a $z$-step size of $0.5 \mu \mathrm{m}$. For axonal myelin reconstructions, recut and restained $40 \mu \mathrm{m}$ slices were imaged at $63 \times$ magnification with $1 \times$ digital zoom and a $z$-step size of $0.5 \mu \mathrm{m}$.

All images were transferred to Neurolucida 360 software (version 2.8; MBF Bioscience) and reconstructed using interactive tracing with the directional kernels method. Reconstructed soma, axon, and myelin segments were analyzed with Neurolucida Explorer (MBF Bioscience). Axons were easily identified as the thinnest, smoothest, and most highly branched processes originating from either the soma or primary dendrite. In addition, axons seemed to branch at more obtuse $\geq 90^{\circ}$ angles from one another, often turning back toward the soma, whereas dendrites branched at smaller angles $\left(<90^{\circ}\right)$, continuing a trajectory away from the soma. All reconstructed cells showed a classical basket cell morphology (DeFelipe et al., 2013), which is consistent with a recent study showing absence of chandelier cells beyond mPFC layer II (Miyamae et al., 2017).

Myelinated axonal segments were defined as the circumferential bordering of a streptavidin-labeled axon by an $\mathrm{MBP}^{+}$myelin signal. Myelin segments that exited a slice were removed from subsequent analysis. No spatial corrections were made for tissue shrinkage.

Transduction efficiency and specificity, as well as oligodendrocyte number, were measured in transduced regions in the prelimbic area of the mPFC (bregma: +2.30 till $+1.70 \mathrm{~mm}$ ) of brain slices from transcardially perfused mice. Stacked confocal images were obtained at $20 \times$ with $1 \times$ digital zoom and a $z$-step size of $3 \mu \mathrm{m}$. A $467 \mu \mathrm{m} \times 467 \mu \mathrm{m} \times 12 \mu \mathrm{m}$ counting frame was established for manual counting using the multipoint tool in Fiji image analysis software (version 2.0.0). Colocalization with PV was defined as a mCherry- or GFP-labeled soma overlapping with $\mathrm{PV}^{+}$soma signal.

Statistical analysis. Statistical analysis was performed using IBM SPSS software version 23. All datasets were examined using Shapiro-Wilk test for normality. Datasets with normal distributions were analyzed for significance using unpaired or paired Student's two-tailed $t$ test or repeated- 


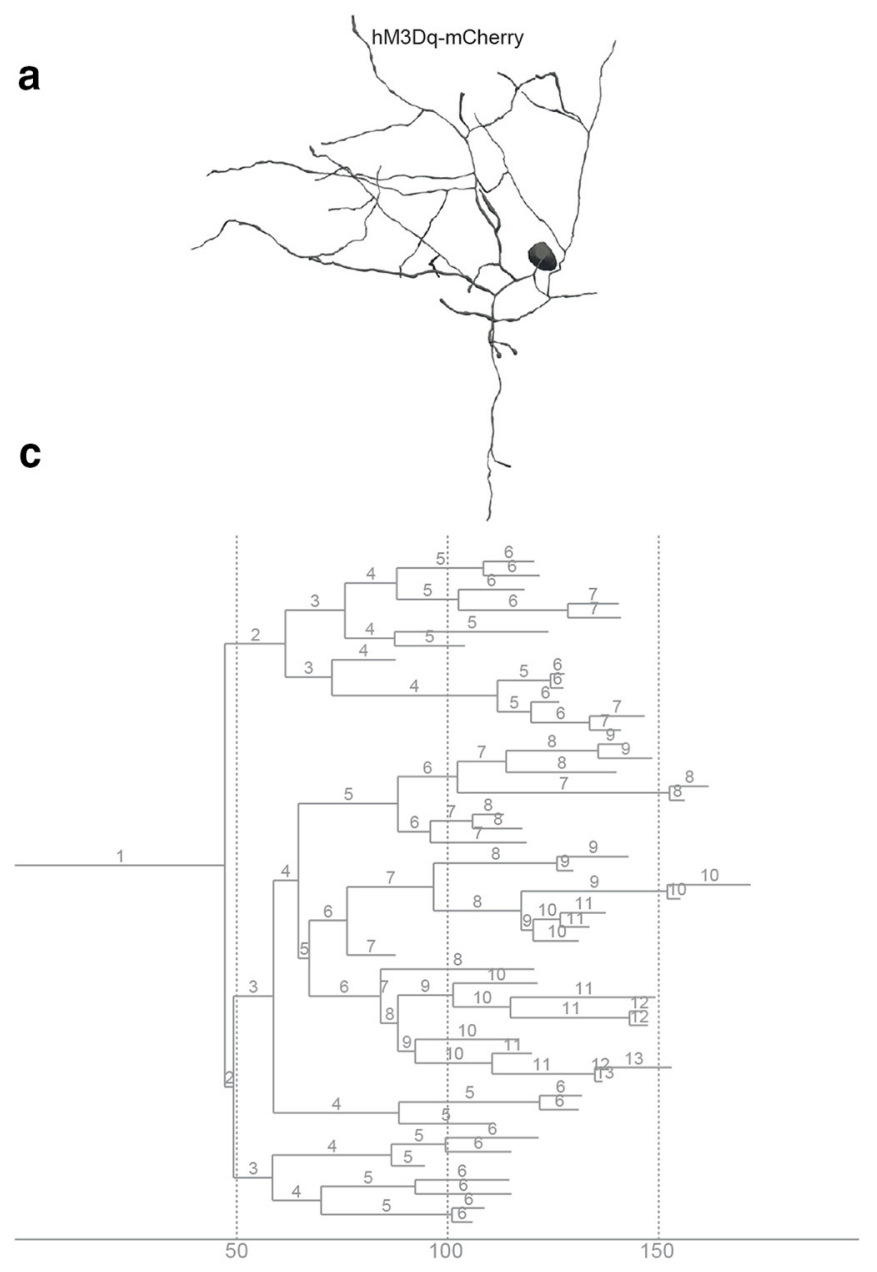

e

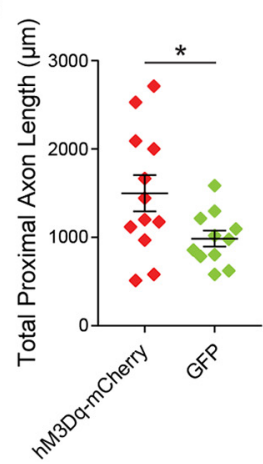

f

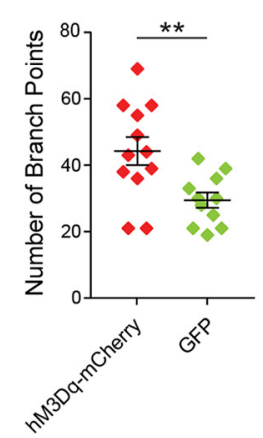

b

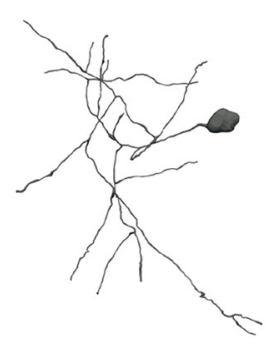

d

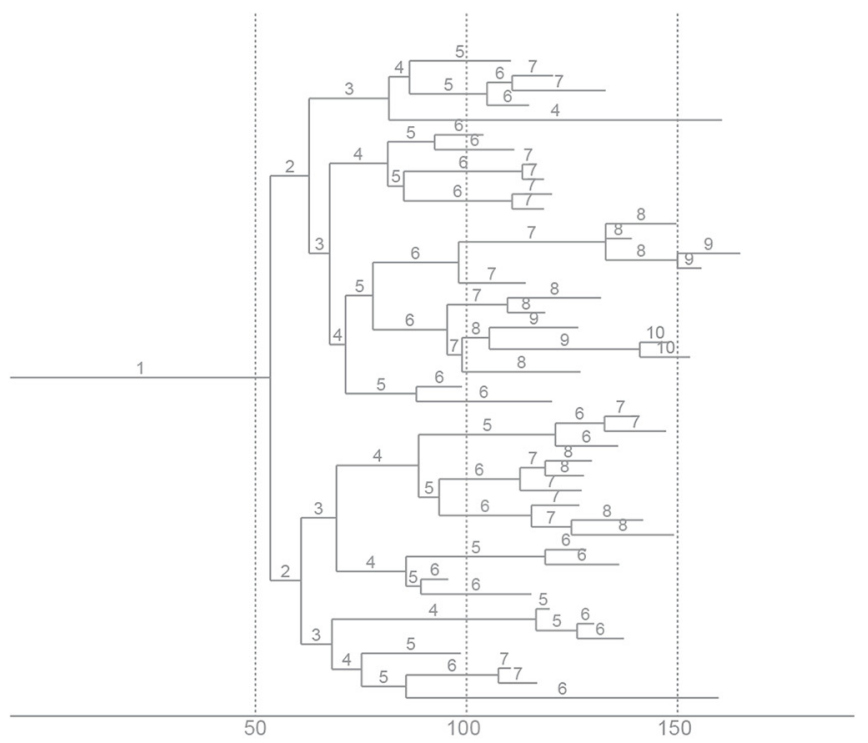

h

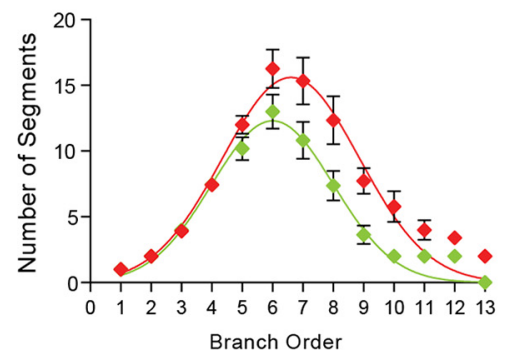

Figure 6. Branch structure analysis. (a,b) Representative proximal axon reconstruction from hM3Dq-mCherry ${ }^{+} \boldsymbol{a}$, and GFP ${ }^{+} \boldsymbol{b}$, cells. (c, $\left.\boldsymbol{d}\right)$ Corresponding axonal dendrogram of hM3Dq-mCherry ${ }^{+}$and GFP ${ }^{+}$cells shown in $\boldsymbol{a}$, and $\boldsymbol{b}$.. Branch orders are centrifugally designated. Horizontal axis is in micrometers. $\boldsymbol{e}$, hM3Dq-mCherry ${ }^{+}$cells (red diamonds) have a

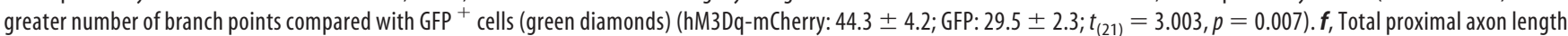
is greater in hM3Dq-mCherry ${ }^{+}$compared with GFP ${ }^{+}$cells (hM3Dq-mCherry: $1499.9 \pm 205.9 \mu \mathrm{m}$; GFP: $\left.985.4 \pm 90.9 \mu \mathrm{m} ; t_{(21)}=2.214, p=0.038\right) . \boldsymbol{g}$, hM3Dq-mCherry ${ }^{+}$cells exhibited an increased number of axonal segments on higher order ( $\geq$ fifth branch order) axonal segments $\left(F_{(12,252)}=3.428, p<0.001\right)$, while $\boldsymbol{h}$, interbranch point distance remained unchanged $\left(F_{(11,44)}=0.712, p<0.721\right) .{ }^{* *} p<0.01 ;{ }^{*} p<0.05$. n.s., Nonsignificant. Unpaired Student's two-tailed $t$ test was used in $\boldsymbol{e}$ and $\boldsymbol{f}$; repeated-measures ANOVA was used in $\boldsymbol{g}$ and $\boldsymbol{h}$. Scale bars indicate mean \pm SEM.

measures ANOVA measures followed by Tukey's post hoc test. Datasets with non-normal distributions were analyzed using Mann-Whitney $U$ test. Significance threshold was set at $p<0.05$ and, herein, exact $p$-values values are provided except when $p<0.001$. All data are expressed as mean \pm SE. On the basis of previously published datasets (Stedehouder et al., 2017), we chose similar sample sizes for all experiments performed. Results are the combination of three animal cohorts that showed similar results.
Results

\section{Chemogenetic activation increases parvalbumin} interneuron myelination

We used in vivo cell-specific expression of activating DREADD (Armbruster et al., 2007), followed by ex vivo whole-cell electrophysiology and single-cell axonal reconstructions (Fig. 1a). Adult $P V::$ cre mice (Hippenmeyer et al., 2005) received bilateral stereo- 
tactic injections in the mPFC using adeno-associated viruses (AAV) with cre-dependent expression of unilateral hM3Dq-mCherry and contralateral GFP (Fig. $1 b, c)$. Four weeks after transduction, mice were given intraperitoneal administrations of $\mathrm{CNO}$ ( $1 \mathrm{mg} / \mathrm{kg}$, twice daily) for 14 consecutive days. Viral transduction was highly specific for $\mathrm{PV}^{+}$cells with a similarly high cell-type specificity of hM3Dq-mCherry and GFP vectors (Fig. $1 d, e)$. Sixteen hours after the last intraperitoneal CNO injection, ex vivo whole-cell recordings with post hoc biocytin labeling were performed in hM3DqmCherry $^{+}$cells and contralateral $\mathrm{GFP}^{+}$ cells from mPFC layer $\mathrm{V}$ (Fig. 2a,b). hM3Dq-mCherry $^{+}$and GFP ${ }^{+}$cells exhibited subthreshold membrane potential oscillations, a suprathreshold high-frequency nonadapting pattern of AP firing, and a large-amplitude fAHP, consistent with a fast-spiking, $\mathrm{PV}^{+}$interneuron identity. No differences were observed between hM3Dq-mCherry ${ }^{+}$and $\mathrm{GFP}^{+}$cells in baseline membrane properties or single AP characteristics (Fig. $2 c-j$ ).

To determine the influence of DREADD receptor activation on $\mathrm{PV}^{+}$interneurons, we performed ex vivo electrophysiological recordings of hM3Dq-mCherry ${ }^{+}$and $\mathrm{GFP}^{+}$ cells in the presence of CNO (Fig. 3a). Local application of $\mathrm{CNO}$ resulted in membrane depolarization, followed by a robust increase in firing frequency of hM3Dq-mCherry ${ }^{+}$cells (Fig. 3b). Similarly, bath application of CNO (5 $\mu \mathrm{M})$ induced an $\sim 5 \mathrm{mV}$ membrane depolarization in hM3Dq-mCherry ${ }^{+}$cells (Fig. $3 c$ ), whereas no changes were observed in $\mathrm{GFP}^{+}$cells (Fig. $3 d$ ). Therefore, CNO administration selectively increased activity in hM3Dq-mCherry ${ }^{+}$cells.

We next sought to determine whether DREADD-mediated activation of $\mathrm{PV}^{+}$ interneurons modulates their myelination. Therefore, we performed Neurolucida reconstructions of proximal axons of biocytin-labeled hM3Dq-mCherry ${ }^{+}$(Fig. $4 a, c, f$ ) and $\mathrm{GFP}^{+}$(Fig. 4b,c,g) cells, including myelination (Fig. $4 e$ ). hM3DqmCherry ${ }^{+}$and $\mathrm{GFP}^{+}$cells were located at a similar depth within the mPFC (Fig. 4d). Consistent with previous findings in $\mathrm{PV}^{+}$ interneurons (Stedehouder et al., 2017), all reconstructed hM3Dq-mCherry ${ }^{+}$and $\mathrm{GFP}^{+}$cells exhibited axonal myelination (hM3Dq-mCherry: 14/14 cells, 100\%; GFP: 12/12 cells, 100\%) (Fig. 4h). However, hM3Dq-mCherry ${ }^{+}$cells exhibited an increase of total length of axonal myelination per neuron (Fig. 4i) driven primarily by an increase in the number of a

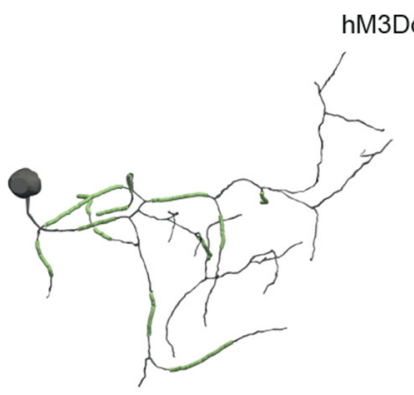

b

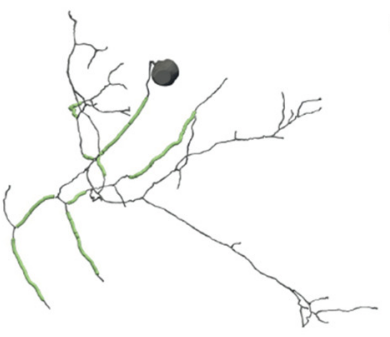

GFP
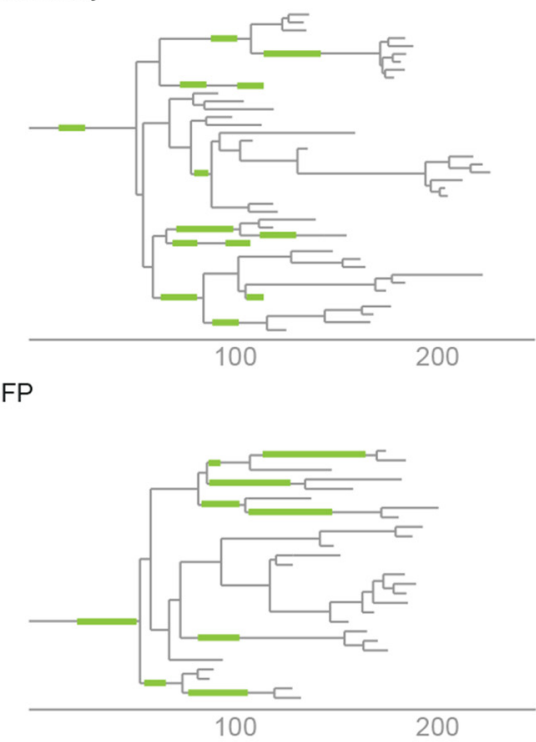

C

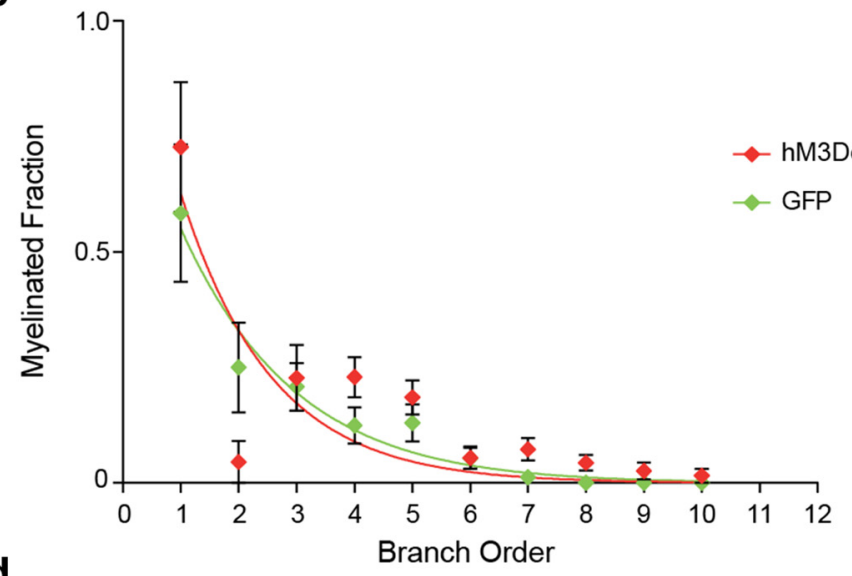

d

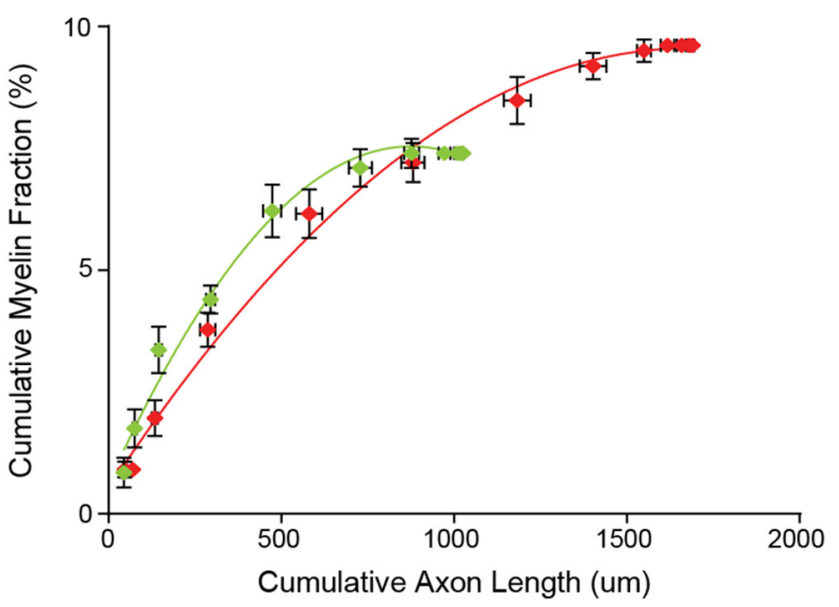

Figure 7. Enhanced segmental myelination is proportional to the elaboration of axonal morphology. $\boldsymbol{a}, \boldsymbol{b}$, Representative $\mathrm{PV}{ }^{+}$ interneuron reconstruction (left) and corresponding axonal dendrogram (right) for hM3Dq-mCherry ${ }^{+}(\boldsymbol{a})$ and GFP ${ }^{+}$cells $(\boldsymbol{b})$. Myelinated segments are shown in green. Horizontal axis is in micrometers. c, Both hM3Dq-mCherry ${ }^{+}{ }^{+}$cells (red diamonds) and $\mathrm{GFP}^{+}$cells (green diamonds) exhibit a decreasing myelination fraction over increasing branch order $\left(F_{(12,252)}=23.823, p<\right.$ 0.001, repeated-measures ANOVA, main effect of branch order). hM3Dq-m(herry ${ }^{+}$cells have a similar proportion of myelinated segments as GFP ${ }^{+}$cells across the entire axonal arbor $\left(F_{(12,252)}=1.206, p=0.279\right.$, repeated-measures ANOVA). $\boldsymbol{d}$, Consistent with the elaboration of their axonal arborization, $\mathrm{hM} 3 \mathrm{Dq}$-mCherry ${ }^{+}$cells contain myelinated segments on more distally extended axonal segments. Scale bars indicate mean \pm SEM. 
a

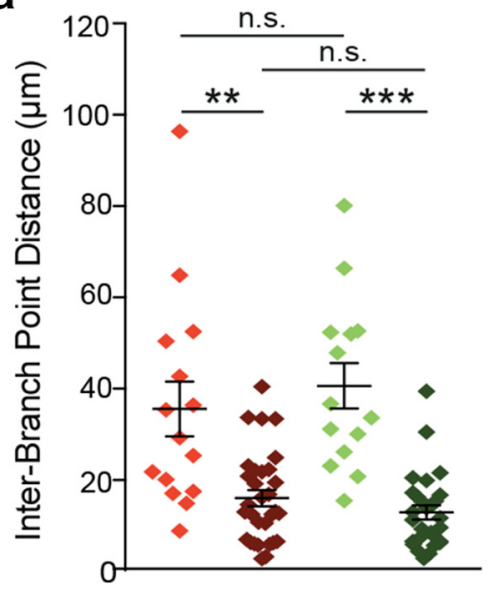

b

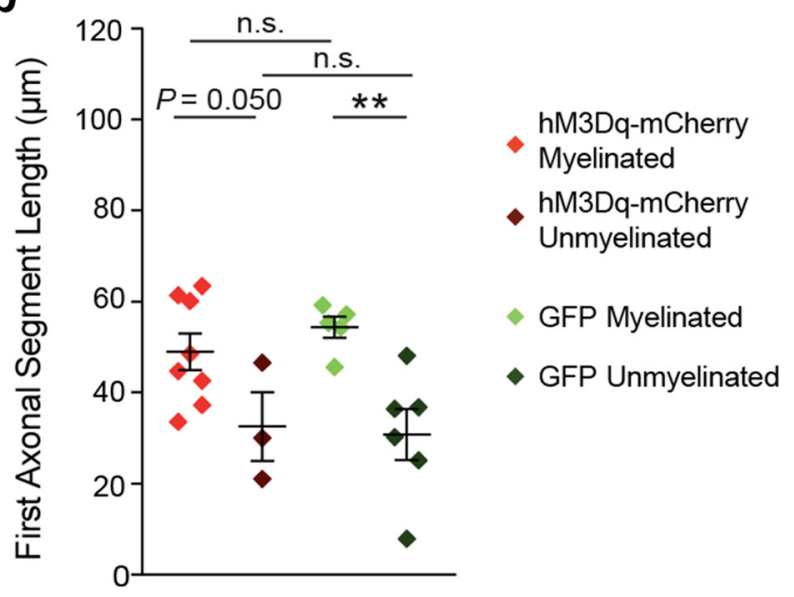

Figure 8. The interbranch distance threshold for segmental myelination remains unchanged. $\boldsymbol{a}$, Quantification of interbranch point distance for myelinated versus unmyelinated segments (second to fifth branch order). Myelinated axonal segments for hM3Dq-mCherry ${ }^{+}$(red diamonds) and GFP ${ }^{+}$cells (green diamonds) are significantly longer than unmyelinated axonal segments (brown and dark green, respectively; hM3Dq-mCherry: $t_{(83)}=3.554, p=0.002 ; \mathrm{GFP}: t_{(71)}=5.949, p<0.001$ ). Length of neither myelinated, nor unmyelinated, segments differed between hM3Dq-mCherry ${ }^{+}$or GFP ${ }^{+}$cells (hM3Dq-mCherry myelinated:36.2 $\pm 5.3 \mu \mathrm{m} ; \mathrm{hM3Dq-mCherry} \mathrm{unmyelinated:} 16.6 \pm 1.6 \mu \mathrm{m} ; \mathrm{GFP}$ myelinated:41.0 \pm 4.3 $\mu \mathrm{m}$ : GFP ${ }^{+}$unmyelinated: $13.5 \pm$ $1.7 \mu \mathrm{m}) . n=3$ cells per region. n.S., Nonsignificant, $t_{(36)}=-0.699, p=0.489$ for myelinated and $t_{(118)}=1.325, p=0.188$ for unmyelinated segments, respectively. $\boldsymbol{b}$, The first axonal branch point was located closer to the soma when it arose before, rather than after, the first internode in both hM3Dq-mCherry ${ }^{+}$and GFP ${ }^{+}$cells. hM3Dq-mCherry: $t_{(11)}=2.202, p=0.050 ; G$ GP: $t_{(11)}=$ $4.025, p=0.002$. n.S., Nonsignificant, $t_{(14)}=-1.342, p=0.201$ for myelinated and $t_{(7)}=0.188, p=0.856$ for unmyelinated segments, respectively. ${ }^{* *} p<0.001$; ${ }^{* *} p<0.01$. Unpaired Student's two-tailed $t$ tests in $\boldsymbol{a}$ and $\boldsymbol{b}$. Scale bars indicate mean \pm SEM.

internodes (Fig. 4j). Internode length showed a trend toward longer internodes in hM3Dq-mCherry ${ }^{+}$cells but was statistically unchanged (Fig. 4k). Topographical analysis of axonal reconstructions revealed that the enhanced myelination of hM3DqmCherry ${ }^{+}$cells occurred along fourth to ninth axonal branch order segments (Fig. 4l), for which hM3Dq-mCherry ${ }^{+}$cells exhibited a significantly higher axonal branch order of distal myelination compared with $\mathrm{GFP}^{+}$cells (Fig. $4 n$ ); the initial onset of myelination was unchanged (Fig. $4 \mathrm{~m}$ ). Together, these data show that chemogenetic activation of $\mathrm{PV}^{+}$interneurons enhances their myelination through an increased number and more distally extended distribution of axonal internodes.

\section{Cell-specific activation results in axon morphology changes} We next sought to determine whether changes in axonal morphology might underlie the observed increase in total myelination on DREADD-stimulated $\mathrm{PV}^{+}$interneurons. Therefore, we reconstructed the axon of each cell, beginning from the axon initial segment until the occurrence of a string of en passant boutons ( $\geq 3$ consecutive boutons on a single axonal branch located within $15 \mu \mathrm{m}$ ) on each terminal branch. Consistently, DREADDstimulated $\mathrm{PV}^{+}$interneurons had a significantly more elaborated axonal morphology compared with $\mathrm{GFP}^{+}$controls (Figs. $5 a, b$, $6 a, b)$. Using Sholl analysis, hM3Dq-mCherry ${ }^{+}$cells exhibited a greater number of intersections and longer axonal length compared with $\mathrm{GFP}^{+}$cells (Fig. $5 c, d$ ). Moreover, branch structure analysis (Fig. $6 a-d$ ) also confirmed that hM3Dq-mCherry ${ }^{+}$cells had a longer axonal length (Fig. 6e) and an increased number of branch points (Fig. $6 f$ ), beginning from the fifth branch order distally (Fig. $6 g$ ). The average interbranch point distance also remained unchanged (Fig. 6h). Together, these data indicate that $\mathrm{PV}^{+}$interneurons exhibit a robust and highly specific activitydependent elaboration of their axonal morphology after in vivo stimulation in the adult neocortex.

\section{Activity-driven myelin increases are proportional to axonal morphology changes}

Given that DREADD-stimulated $\mathrm{PV}^{+}$interneurons exhibit increased myelination and altered axonal morphology, we investigated whether the increase in myelination was proportional to the change in axonal complexity. For each cell, we examined the proportion of axonal segments per branch order that contained internodes (myelination fraction). Both hM3Dq-mCherry ${ }^{+}$and $\mathrm{GFP}^{+}$cells showed a progressively decreasing myelination fraction with increasing branch order (Fig. $7 a-c$ ). Moreover, hM3DqmCherry $^{+}$cells exhibit a similar myelination fraction extending to the distal limit of $\mathrm{GFP}^{+}$cells (Fig. 7c), beyond which hM3DqmCherry $^{+}$cells exhibit additional myelinated segments along their extended axonal length (Fig. 7d). Together, these data suggest that the activity-dependent increase in myelination of $\mathrm{PV}^{+}$ interneurons is predominantly mediated by the elaboration of axon morphology.

\section{Myelination is restricted by axonal distance between branch points}

Previous studies have reported that proximal axon myelination most commonly occurs on uninterrupted axonal segments of at least $15 \mu \mathrm{m}$ (Stedehouder et al., 2017). Therefore, we investigated whether activity-induced myelination changed these requirements. We quantified interbranch point distances from the soma up to fifth-order axonal segments, including whether these segments contained an internode. Unmyelinated interbranch point segments were consistently shorter than corresponding myelinated segments in both $\mathrm{GFP}^{+}$cells and hM3Dq-mCherry ${ }^{+}$cells (Fig. 8a). Overall, interbranch segments $>40 \mu \mathrm{m}$ were frequently myelinated $(91.6 \%)$, whereas interbranch segments $<15 \mu \mathrm{m}$ tended to be unmyelinated (96.2\%). An analogous dichotomy was also evident in the location of the first axonal branch point, which was positioned closer to the soma when it arose before, compared with after, the first internode of both hM3Dq-mCherry ${ }^{+}$and $\mathrm{GFP}$ cells ${ }^{+}$(Fig. 8b). These findings suggest that the activity- 
a rAAV5/hSyn-DIO-hM3Dq-mCherry and rAAV5/hSyn-DIO-GFP

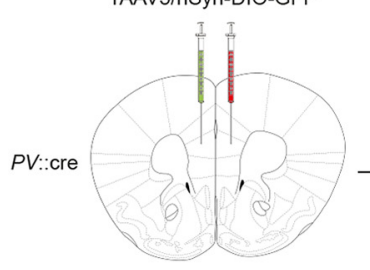

Twice-Daily CNO

Injections
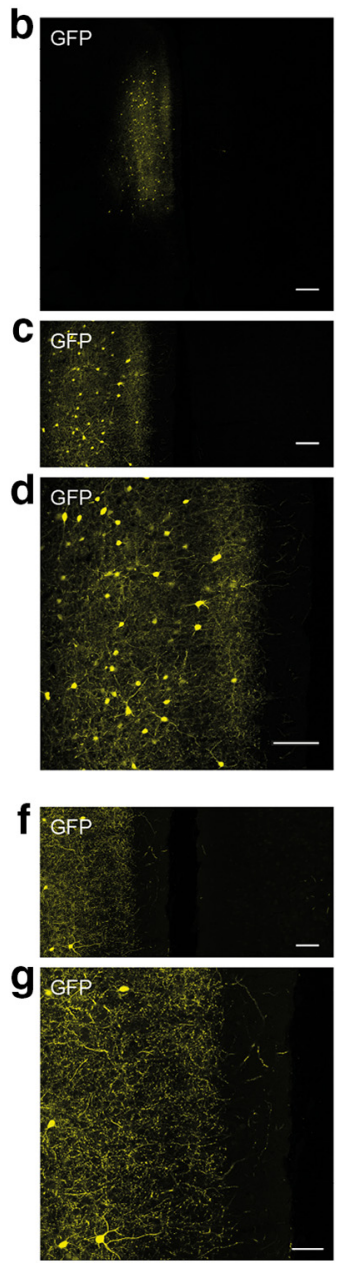
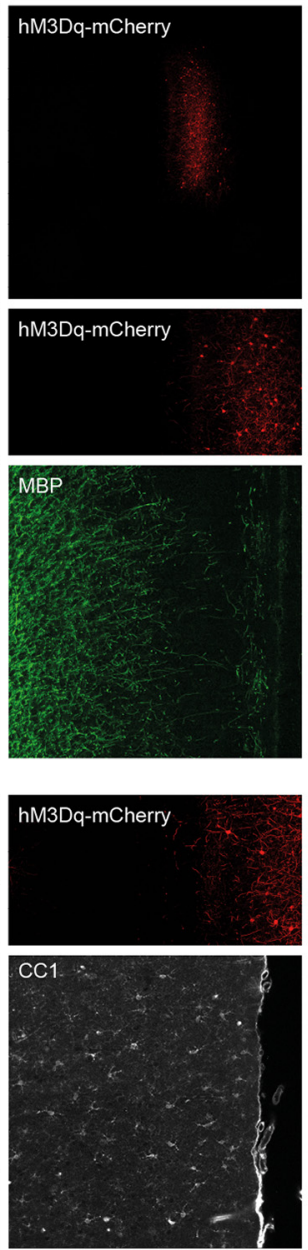
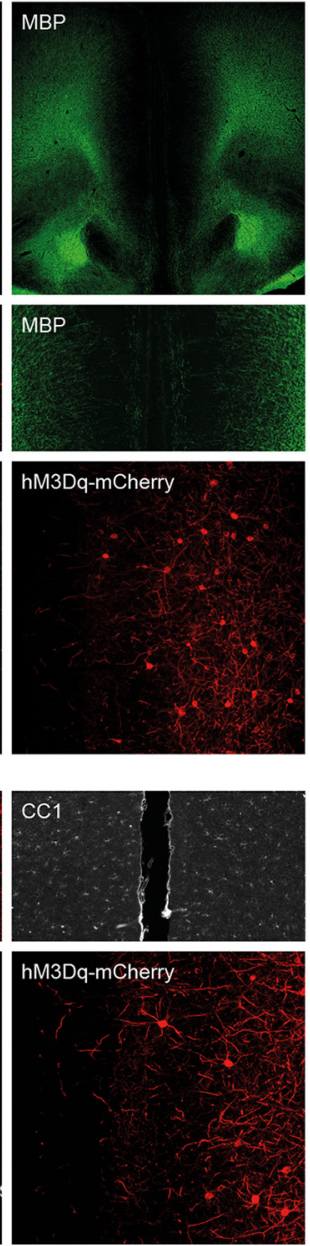
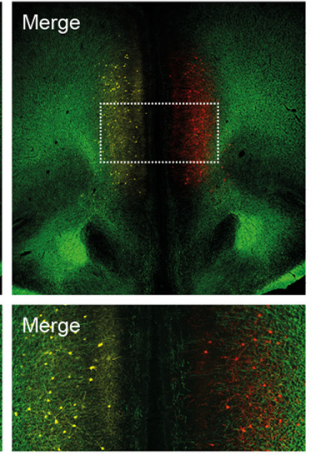

MBP
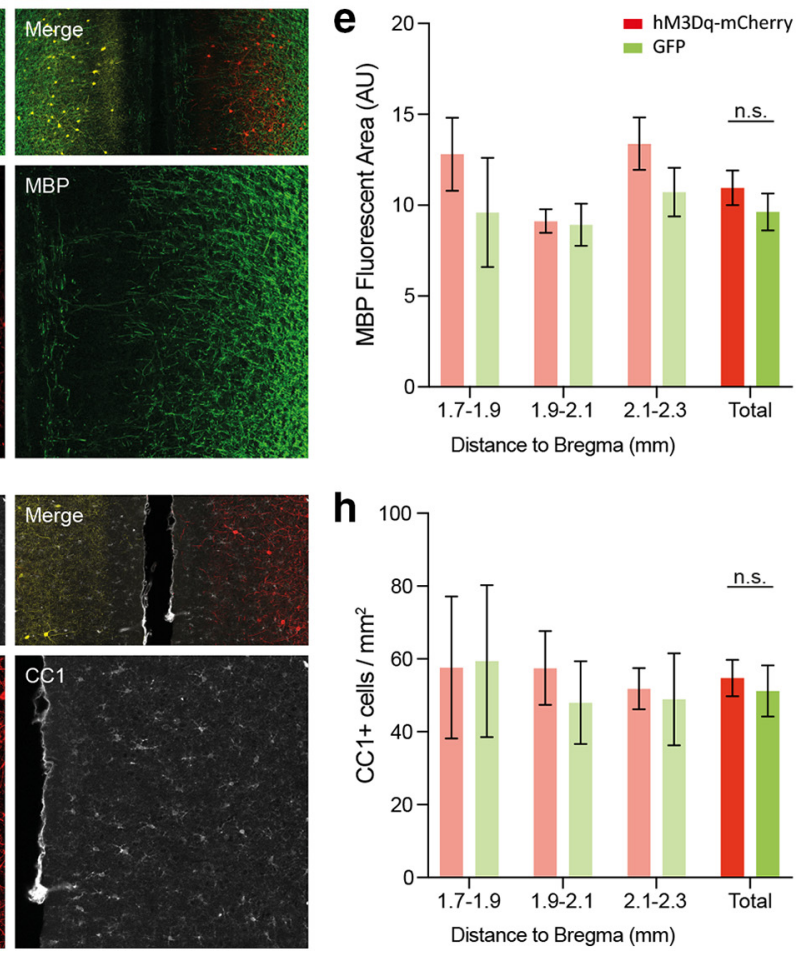

Figure 9. No observed changes in oligodendrocyte density or total myelin content. $\boldsymbol{a}$, Experimental design. Adult $P V$ ::cre mice received pseudorandomly assigned unilateral stereotactic injections of cre-dependent hM3Dq-mCherry and contralateral GFP virus in mPFC. Twenty-eight days after surgery, mice received twice daily intraperitoneal administration of $1 \mathrm{mg} / \mathrm{kg}$ CN0 for $14 \mathrm{~d}$. One day later, mice were killed for immunofluorescence labeling. $\boldsymbol{b}$, Confocal overview images of myelin (MBP; green) labeling from GFP (yellow) and hM3Dq-mCherry (red) transduced hemispheres; white box indicates quantified region. Scale bar, $250 \mu \mathrm{m}$ c, Magnified confocal images of the boxed area in $\boldsymbol{b}$. Scale bar, $50 \mu \mathrm{m} \boldsymbol{d}$, High-magnification image of myelin (MBP; green) within the GFP (yellow) and hM3Dq-mCherry (red) transduced hemispheres. Scale bar, $50 \mu \mathrm{m} . e, \mathrm{MBP}$ fluorescent area is similar between GFP and hM3Dq-mCherry transduced hemispheres $\left(t_{(3)}=0.908, p=0.431 ; n=\right.$ 4 mice). $f$, Confocal overview image of CC ${ }^{+}$oligodendrocytes (gray) in GFP (yellow) and hM3Dq-mCherry (red) transduced hemispheres. Scale bar, $50 \mu m$. $g$, Higher-magnification confocal image of $\mathrm{CC}^{+}{ }^{+}$oligodendrocytes (gray) in GFP (yellow) and hM3Dq-mCherry (red) transduced hemispheres. Scale bar, $50 \mu \mathrm{m} . \boldsymbol{h}$, Density of CC ${ }^{+}$oligodendrocytes was similar between hemispheres $\left(t_{(7)}=-0.693, p=0.511 ; n=2\right.$ mice). Paired Student's two-tailed $t$ test was used in $\boldsymbol{e}$ and $\boldsymbol{h}$. Scale bars indicate mean \pm SEM. n.s., Nonsignificant.

driven increase of $\mathrm{PV}^{+}$interneuron myelination is proportional to the increase of total axonal length while maintaining a similar topography of axonal morphology and myelination.

\section{No alterations in total myelin content or}

oligodendrocyte number

Prior studies using optogenetic and chemogenetic pyramidal cell activation have demonstrated substantial increases in total myelin content and oligodendrocyte lineage cell density (Gibson et al., 2014; Mitew et al., 2018). Therefore, we investigated the celltype specificity of the activity-dependent changes in $\mathrm{PV}^{+}$axonal myelination by quantifying both total myelin content and oligodendrocyte density in the surrounding volume. We performed immunofluorescent stainings for myelin (MBP) and mature oligodendrocytes (CC1) in hM3Dq-mCherry ${ }^{+}$and $\mathrm{GFP}^{+}$transduced areas (Fig. 9a). In contrast to previous studies involving pyramidal cell stimulation, we did not find evidence for changes of total myelin content (Fig. $9 b-e$ ) or oligodendrocyte density (Fig. $9 f-h$ ) following stimulation of $\mathrm{PV}^{+}$interneurons. Accordingly, the observed activity-dependent changes in $\mathrm{PV}^{+}$axonal morphology and myelination appear likely to be cell autonomous. 


\section{Discussion}

Here, we investigated whether in vivo activity-dependent myelination occurs in neocortical fast-spiking, $\mathrm{PV}^{+}$interneurons. Using cell-specific chemogenetic activation followed by single-cell reconstructions of $\mathrm{PV}^{+}$interneurons in the adult mouse mPFC, we found that in vivo stimulation of $\mathrm{PV}^{+}$interneuron activity induced an $\sim 50 \%$ increase in proximal axonal length with a proportional increase in myelination. These findings add to the understanding of dynamic myelination, but our results suggest that, at least for $\mathrm{PV}^{+}$interneurons, this is mediated to a significant extent by activity-dependent plasticity of axonal morphology.

Using single-cell reconstructions allowed us to document comprehensively the position of each myelinated segment along the axon, in contrast to previous studies using larger-scale analyses (Gibson et al., 2014). We found that stimulated cells exhibited increased myelination of more distal axon segments (branch order $\geq 4$ ), whereas myelination did not differ on more proximal branch orders. Furthermore, due to bilateral transfection with either DREADDs or GFP, we could reconstruct cells from both hemispheres under similar conditions, thereby minimizing possible experience-dependent variation. Finally, our studies were performed in adult mice, thereby reducing the likelihood of neurodevelopmental interactions. As a corollary, whether activity-dependent $\mathrm{PV}^{+}$myelination is regulated similarly during neurodevelopment is an important question that remains to be answered.

A limitation of the current study is that we could not follow axonal and myelination changes longitudinally over time. Therefore, the time course of the observed changes of axonal morphology and myelination remain unknown, as well as a definitive confirmation that the changes in axonal morphology precede the increase in myelination. Moreover, it remains unknown which specific axonal parameters govern the increase of $\mathrm{PV}^{+}$interneuron myelination. Our findings suggest that a substantial proportion of the increase in myelination is mediated by an activity-induced elaboration of $\mathrm{PV}^{+}$interneuron axonal arborization (Yamada et al., 2010) that is subsequently myelinated. Another candidate is axon diameter, which has been shown to change rapidly upon neuronal activity in CA3 pyramidal cells (Chéreau et al., 2017) and has been demonstrated to function as a critical biophysical threshold permissive for myelination (Lee et al., 2012; Bechler et al., 2015). Moreover, an activity-dependent modulation of vesicular release probability could also be an important determinant because axonal vesicular release has been shown to regulate the differentiation to myelinating oligodendrocytes of oligodendrocyte progenitor cells in close proximity to unmyelinated axonal segments (Mensch et al., 2015; Wake et al., 2015).

The increase of axonal myelination appears to result from the addition of internodes because the distribution of internode length is largely preserved (Fig. $4 k$ ). Consistent with previous findings (Stedehouder et al., 2017), we also found that the pattern of myelination along axons of stimulated $\mathrm{PV}^{+}$interneurons is constrained by a similar interbranch segment length threshold (Fig. 8). This suggests that, although neuronal activity can modulate axonal morphology dynamically, there is as yet no evidence for activity-dependent plasticity of the fundamental biophysical parameters dictating the eligibility of myelination at a given axonal segment.

Previous reports demonstrated that cell-type-specific stimulation of cortical pyramidal neurons lead to observable changes of total myelin content and oligodendrocyte density. We similarly assessed cell-type specificity after chemogenetic activation of
$\mathrm{PV}^{+}$interneurons. However, we did not find changes in oligodendrocyte density or overall myelin labeling. We suggest two possibilities for the absence of an observable difference of these metrics. First, given that $\mathrm{PV}^{+}$interneurons contribute only a small minority of the total myelin content in the mPFC (Stedehouder et al., 2017) and that virally labeled cells constitute only a subset of $\mathrm{PV}^{+}$interneurons within the transduced areas, the possibility exists that changes in the number of oligodendrocytes due to $\mathrm{PV}^{+}$activation might have been too small to be observed using volumetric quantification. Moreover, with regard to total myelin content, the limitation of a volumetric quantification might therefore also be considered likely on the basis of the demonstrated increase of myelination per chemogenetically activated $\mathrm{PV}^{+}$interneuron (Fig. 4). The second non-mutually exclusive possibility is predicated upon the established function of $\mathrm{PV}^{+}$ interneurons as strong modulators of local network activity $(\mathrm{Hu}$ et al., 2014). In this scenario, $\mathrm{PV}^{+}$interneuron-mediated inhibition of principal cell firing might lead to reductions in myelination of an equivalent magnitude as the increase in myelination of $\mathrm{PV}^{+}$interneurons.

Here, we identified a novel form of activity-dependent myelination mediated by axonal morphological plasticity of $\mathrm{PV}^{+}$interneurons. These findings contribute to the increasing evidence demonstrating the dynamic plasticity of adult neocortical myelination and axonal morphology.

\section{References}

Armbruster BN, Li X, Pausch MH, Herlitze S, Roth BL (2007) Evolving the lock to fit the key to create a family of $\mathrm{G}$ protein-coupled receptors potently activated by an inert ligand. Proc Natl Acad Sci U S A 104:51635168. CrossRef Medline

Bechler ME, Byrne L, Ffrench-Constant C (2015) CNS myelin sheath lengths are an intrinsic property of oligodendrocytes. Curr Biol 25:24112416. CrossRef Medline

Chang KJ, Redmond SA, Chan JR (2016) Remodeling myelination: implications for mechanisms of neural plasticity. Nat Neurosci 19:190-197. CrossRef Medline

Chéreau R, Saraceno GE, Angibaud J, Cattaert D, Nägerl UV (2017) Superresolution imaging reveals activity-dependent plasticity of axon morphology linked to changes in action potential conduction velocity. Proc Natl Acad Sci U S A 114:1401-1406. CrossRef Medline

DeFelipe J, López-Cruz PL, Benavides-Piccione R, Bielza C, Larrañaga P, Anderson S, Burkhalter A, Cauli B, Fairén A, Feldmeyer D, Fishell G, Fitzpatrick D, Freund TF, González-Burgos G, Hestrin S, Hill S, Hof PR, Huang J, Jones EG, Kawaguchi Y, et al. (2013) New insights into the classification and nomenclature of cortical GABAergic interneurons. Nat Rev Neurosci 14:202-216. CrossRef Medline

Etxeberria A, Hokanson KC, Dao DQ, Mayoral SR, Mei F, Redmond SA, Ullian EM, Chan JR (2016) Dynamic modulation of myelination in response to visual stimuli alters optic nerve conduction velocity. J Neurosci 36:6937-6948. CrossRef Medline

Fields RD (2015) A new mechanism of nervous system plasticity: activitydependent myelination. Nat Rev Neurosci 16:756-767. CrossRef Medline

Gibson EM, Purger D, Mount CW, Goldstein AK, Lin GL, Wood LS, Inema I, Miller SE, Bieri G, Zuchero JB, Barres BA, Woo PJ, Vogel H, Monje M (2014) Neuronal activity promotes oligodendrogenesis and adaptive myelination in the mammalian brain. Science 344:1252304. CrossRef Medline

Hines JH, Ravanelli AM, Schwindt R, Scott EK, Appel B (2015) Neuronal activity biases axon selection for myelination in vivo. Nat Neurosci 18: 683-689. CrossRef Medline

Hippenmeyer S, Vrieseling E, Sigrist M, Portmann T, Laengle C, Ladle DR, Arber S (2005) A developmental switch in the response of DRG neurons to ETS transcription factor signaling. PLoS Biol 3:e159. CrossRef Medline

Hu H, Gan J, Jonas P (2014) Interneurons. Fast-spiking, parvalbumin ${ }^{+}$ GABAergic interneurons: from cellular design to microcircuit function. Science 345:1255263. CrossRef Medline

Lee S, Leach MK, Redmond SA, Chong SY, Mellon SH, Tuck SJ, Feng ZQ, Corey JM, Chan JR (2012) A culture system to study oligodendrocyte 
myelination processes using engineered nanofibers. Nat Methods 9:917922. CrossRef Medline

Makinodan M, Rosen KM, Ito S, Corfas G (2012) A critical period for social experience-dependent oligodendrocyte maturation and myelination. Science 337:1357-1360. CrossRef Medline

McKenzie IA, Ohayon D, Li H, de Faria JP, Emery B, Tohyama K, Richardson WD (2014) Motor skill learning requires active central myelination. Science 346:318-322. CrossRef Medline

Mensch S, Baraban M, Almeida R, Czopka T, Ausborn J, El Manira A, Lyons DA (2015) Synaptic vesicle release regulates myelin sheath number of individual oligodendrocytes in vivo. Nat Neurosci 18:628-630. CrossRef Medline

Micheva KD, Wolman D, Mensh BD, Pax E, Buchanan J, Smith SJ, Bock DD (2016) A large fraction of neocortical myelin ensheathes axons of local inhibitory neurons. Elife 5:e15784. CrossRef Medline

Mitew S, Gobius I, Fenlon LR, McDougall SJ, Hawkes D, Xing YL, Bujalka H,
Gundlach AL, Richards LJ, Kilpatrick TJ, Merson TD, Emery B (2018) Pharmacogenetic stimulation of neuronal activity increases myelination in an axon-specific manner. Nat Commun 9:306. CrossRef Medline

Miyamae T, Chen K, Lewis DA, Gonzalez-Burgos G (2017) Distinct physiological maturation of parvalbumin-positive neuron subtypes in mouse prefrontal cortex. J Neurosci 37:4883-4902. CrossRef Medline

Stedehouder J, Couey JJ, Brizee D, Hosseini B, Slotman JA, Dirven CMF, Shpak G, Houtsmuller AB, Kushner SA (2017) Fast-spiking parvalbumin interneurons are frequently myelinated in the cerebral cortex of mice and humans. Cereb Cortex 27:5001-5013. CrossRef Medline

Wake H, Ortiz FC, Woo DH, Lee PR, Angulo MC, Fields RD (2015) Nonsynaptic junctions on myelinating glia promote preferential myelination of electrically active axons. Nat Commun 6:7844. CrossRef Medline

Yamada A, Uesaka N, Hayano Y, Tabata T, Kano M, Yamamoto N (2010) Role of presynaptic and postsynaptic activity in thalamocortical axon branching. Proc Natl Acad Sci U S A 107:7562-7567. CrossRef Medline 